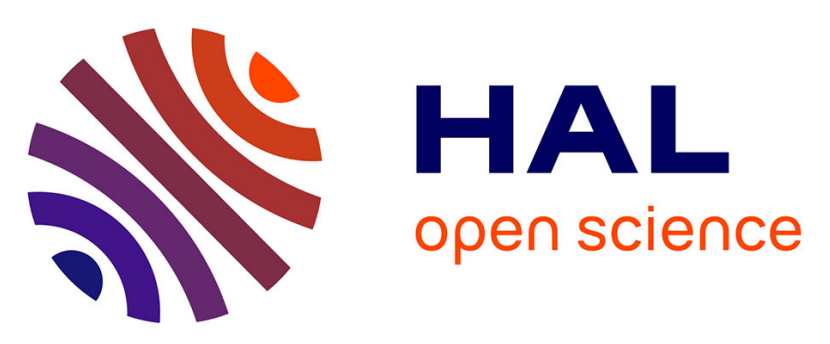

\title{
An Experimental and Computational Study of the Valence Photoelectron Spectra of Halogenated Pyrimidines
}

Patrick O’Keeffe, Paola Bolognesi, Anna Rita Casavola, Daniele Catone, Nicola Zema, Stefano Turchini, Lorenzo Avaldi

\section{To cite this version:}

Patrick O'Keeffe, Paola Bolognesi, Anna Rita Casavola, Daniele Catone, Nicola Zema, et al.. An Experimental and Computational Study of the Valence Photoelectron Spectra of Halogenated Pyrimidines. Molecular Physics, 2009, 107 (19), pp.2025-2037. 10.1080/00268970903120328. hal00519623

\section{HAL Id: hal-00519623 \\ https://hal.science/hal-00519623}

Submitted on 21 Sep 2010

HAL is a multi-disciplinary open access archive for the deposit and dissemination of scientific research documents, whether they are published or not. The documents may come from teaching and research institutions in France or abroad, or from public or private research centers.
L'archive ouverte pluridisciplinaire HAL, est destinée au dépôt et à la diffusion de documents scientifiques de niveau recherche, publiés ou non, émanant des établissements d'enseignement et de recherche français ou étrangers, des laboratoires publics ou privés. 


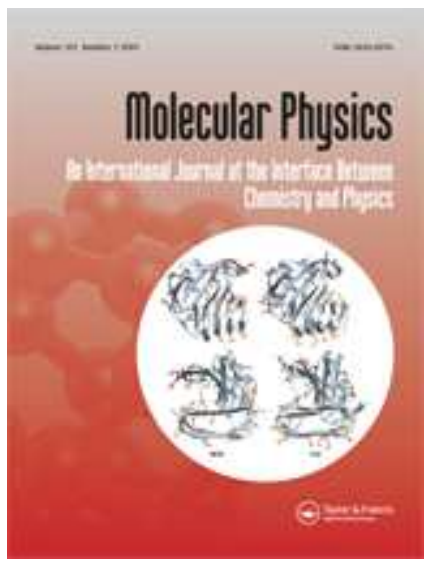

\section{An Experimental and Computational Study of the Valence Photoelectron Spectra of Halogenated Pyrimidines}

\begin{tabular}{|r|l|}
\hline Journal: & Molecular Physics \\
\hline Manuscript ID: & TMPH-2009-0113.R1 \\
\hline Manuscript Type: & Full Paper \\
\hline Author: & 29-May-2009 \\
\hline Complete List of Authors: & $\begin{array}{l}\text { O'Keeffe, Patrick; IMIP } \\
\text { Bolognesi, Paola; CNR, IMIP } \\
\text { Casavola, Anna Rita; CNR, IMIP } \\
\text { Catone, Daniele; CNR, ISM } \\
\text { Zema, Nicola; CNR, ISM } \\
\text { Turchini, Stefano; CNR, ISM } \\
\text { Avaldi, Lorenzo; CNR, IMIP }\end{array}$ \\
\hline Keywords: & $\begin{array}{l}\text { Photoelectron spectra, Halogenated pyrimidines, Substituent } \\
\text { effects, Density functional theory, Electron propagator theory }\end{array}$ \\
\hline \multicolumn{2}{|l}{} \\
\hline $\begin{array}{l}\text { Note: The following files were submitted by the author for peer review, but cannot be converted } \\
\text { to PDF. You must view these files (e.g. movies) online. }\end{array}$ \\
\hline $\begin{array}{l}\text { ManuscriptPyr.tex } \\
\text { Figures.zip }\end{array}$ \\
\hline
\end{tabular}




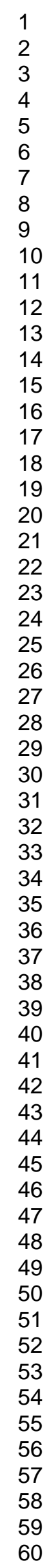

\section{$\$$ Manuscript Central}

URL: http://mc.manuscriptcentral.com/tandf/tmph 


\title{
RESEARCH ARTICLE
}

\section{An Experimental and Computational Study of the Valence Photoelectron Spectra of Halogenated Pyrimidines}

\author{
Patrick O'Keeffe ${ }^{*}{ }^{*}$, Paola Bolognesi $^{a}$, Anna Rita Casavola ${ }^{a}$, Daniele Catone ${ }^{b}$, Nicola \\ Zema $^{b}$, Stefano Turchini ${ }^{b}$, Lorenzo Avaldi ${ }^{a}$ \\ ${ }^{a}$ CNR-IMIP Area della Ricerca di Roma 1, CP 1000016 Monterotondo Scalo, Italy; \\ ${ }^{b}$ CNR-ISM, Via del Fosso del Cavaliere 100, Rome I-00133, Italy \\ (Received 00 Month 200x; final version received 00 Month 200x)
}

\begin{abstract}
The electronic structures of pyrimidine and a selection of its halogen substituted derivatives have been investigated using ultraviolet photoelectron spectroscopy and $a b$ initio quantum chemical methods. Assignments are proposed for all of the features in the PES spectra by comparison with the vertical ionisation energies of the molecular orbitals calculated using the partial third order quasiparticle approximation as applied to electron propagator theory and a corrected density functional method based on the B3LYP functional. The shifts of the outermost five molecular orbitals of the pyrimidine ring structure in the halogen substituted derivatives with respect to the binding energies of the equivalent orbitals in the parent pyrimidine molecule are discussed as a function of the identity and ring position of the halogen atom.
\end{abstract}

Keywords: Photoelectron spectra; Halogenated pyrimidines; Substituent effects; Density functional theory; Electron propagator theory.

\section{Introduction}

Pyrimidines are an important class of organic molecules mainly due to the fact that the pyrimidine ring forms the base structure of three nucleic acids, i.e. uracil, cytosine and thymine. Furthermore, halogenated pyrimidine bases have found applications as radiosensitisers in radiotherapy where, for example, it has been discovered more than 40 years ago that 5-bromodeoxyuridine (an analogue of thymidine) radiosensitises cells $[1,2]$. A deep understanding of valence photoelectron spectra of the halogenated pyrimidines will help a greater understanding of the electronic structure of the halogenated bases. In addition, a study of the valence shell structure of a molecule provides the basis for further studies on the fragmentation of such molecules following both valence shell and inner shell ionisation.

This work is part of an overall investigation of the valence and inner shell electronic structure and electronic spectra of this class of molecules undertaken by probing them with laboratory sources [3] and synchrotron radiation. In particular, results of the present work constitute the basis to interpret the resonant Auger structure produced after innershell excitation.

The photoelectron spectrum (PES) of pyrimidine and some of its derivatives have been studied in the past $[4,5]$, however to the best of our knowledge no work has

\footnotetext{
${ }^{*}$ Corresponding author.
} 
been published on the effect of the halogen substitution of the pyrimidine ring on the valence photoelectron spectrum of the molecule. In particular the valence PES of pyrimidine has been analysed in detail in the work of Holland et al. [4]. This group has also performed a systematic experimental and computational study of the halobenzenes [6, 7], halothiophenes [8-10] and, most recently, the halouracils [11]. In this work we concentrate on the substituent effects of the halogen atoms on the pyrimidine parent molecule as a function of ring position and halogen character. The analysis of experimental valence photoelectron spectra are supported by a detailed computational analysis of the orbitals energies and ionisation potentials.

\section{Experimental Section}

The photoelectron spectra were measured using a resonance noble gas discharge lamp operated on the He I line at $21.22 \mathrm{eV}$ in combination with a home-built hemispherical analyser (mean radius $=60 \mathrm{~mm}$ ). The He I radiation was transported to the interaction region by means of a capillary tube where it intersected the gas flow at an angle of $90^{\circ}$. The kinetic energy of the photoelectrons emitted into an acceptance angle of $\pm 5^{\circ}$ oriented at $90^{\circ}$ with respect to the direction of propagation of the radiation was measured.

Energy calibration of the spectra was achieved by adding a small amount of Argon to the gas flow and the resulting photoelectron peaks at $15.759 \mathrm{eV}$ and $15.937 \mathrm{eV}$, corresponding to the $3 p^{-12} P_{\frac{3}{2}} \mathrm{Ar}^{+} \leftarrow \operatorname{Ar}\left({ }^{1} S_{0}\right)$ and $3 p^{-1}{ }^{2} P_{\frac{1}{2}} \mathrm{Ar}^{+} \leftarrow \operatorname{Ar}\left({ }^{1} S_{0}\right)$ transitions, were then used to correct the energy scale of the molecular photoelectrons. The photoelectron spectra were also corrected for the non-linear transmission of the analyser by measurement of the known spectra of benzene $[12,13]$ and methyl oxirane [14]. The transmission function of our apparatus was extracted by comparing the intensities of the peaks of the literature spectra with the raw intensities of the equivalent spectra recorded using the electron spectrometer used in this work. The different collection angle: magic angle in the case of the reference spectra and $90^{\circ}$ in the case of the electron spectrometer used here was also taken into account by using the $\beta$ parameter for each peak. All spectra were measured at a resolution of $160 \mathrm{meV}$ (FWHM) as determined from the width of the above Argon photoelectron peaks. Furthermore, the low binding energy region of each molecule (typically 9.5 to $13.5 \mathrm{eV}$ ) were scanned at the higher resolution of $75 \mathrm{meV}$ (FWHM). The peak positions were determined using standard peak fitting procedures.

Finally, all compounds were purchased from Sigma Aldrich and used without further purification (see Figure 1). The compounds were introduced into the interaction region via a leak valve where the room temperature vapour pressures of the samples were sufficient to provide a high enough gas density in the interaction region to allow the electron spectra to be recorded.

\section{Computational Details}

All $a b$ initio calculations were performed using the Gaussian03 package of programs [15] where the geometries were optimised at the B3LYP density functional level of theory [16-18] using the split valence plus polarisation basis set $6-311++\mathrm{G}(\mathrm{d}, \mathrm{p})[19]$. These geometries, the resulting vibrational frequencies and total energies can be found in the supporting information section of this article. Subsequently a number of methods were employed to calculate the vertical ionisation energies of the molecules using these geometries in order to achieve a reliable interpretation of their photoelectron spectra. The three computational methods 


\section{Results and Discussion}

\subsection{Pyrimidine}

In order to be able to discuss the effect of the substituents on the electronic structure of the halogenated pyrimidines it is first necessary to briefly re-examine the photoelectron spectrum of the parent molecule: pyrimidine. To this end the He I PES of pyrimidine has been measured and is presented in Figure 2 and the results of the ab initio calculations on this molecule are summarised and compared to the experimental peaks in Table 1.

At the Hartree-Fock (HF) level of theory the ground state valence orbital configuration of pyrimidine in $C_{2 v}$ symmetry is

$$
\begin{aligned}
\text { inner valence: } & \left(1 a_{1}\right)^{2}\left(1 b_{2}\right)^{2}\left(2 a_{1}\right)^{2}\left(2 b_{2}\right)^{2}\left(3 a_{1}\right)^{2}\left(4 a_{1}\right)^{2} \\
\text { outer valence: } & \left(3 b_{2}\right)^{2}\left(5 a_{1}\right)^{2}\left(4 b_{2}\right)^{2}\left(6 a_{1}\right)^{2}\left(1 b_{1}\right)^{2}\left(7 a_{1}\right)^{2} \\
& \left(1 a_{2}\right)^{2}\left(5 b_{2}\right)^{2}\left(2 b_{1}\right)^{2}
\end{aligned}
$$

where the orbitals of $a_{1}$ and $b_{2}$ symmetry correspond to $\sigma$ orbitals while those of $a_{2}$ and $b_{1}$ symmetry correspond to $\pi$ type orbitals. In particular for the outermost 5 molecular orbitals (MOs) we adopt the notation of Lotermoser et al. [5] in which the $5 b_{2}$ and $7 a_{1}$ orbitals are denoted as $n_{N_{-}}$and $n_{N_{+}}$, respectively, and the $2 b_{1}, 1 a_{2}$ and $1 b_{1}$ orbitals are denoted as $\pi_{3}, \pi_{2}$ and $\pi_{1}$ orbitals. These HF molecular orbitals are shown in Figure 3 where it can be seen that the three $\pi$ orbitals are localised above and below the pyrimidine ring while the $n_{N_{-}}$and $n_{N_{+}}$orbitals are principally the nitrogen lone pairs where the + and - symbols indicate symmetric and antisymmetric combinations. The influence of electronegative halogen substituents on the composition and binding energy of these orbitals will be discussed in detail in the following subsection.

The first intriguing point to note from the $a b$ initio calculations lies in the change of the energy ordering of the orbitals on passing from the Hartree-Fock/Koopmans' theorem to the higher level methods involving electron propagator theory (EPT) and the modified density functional theory (DFT) method. These changes, which have already been noted in the past $[4,5]$, include the inversion of the ordering of the HOMO and HOMO-1 as well as the inversion of the HOMO-2 and HOMO3 (see Table 1). This is mainly due to the fact that the energy of the $\pi_{3}$ and $\pi_{2}$ orbitals change very little while the energy of the $n_{N_{-}}$and $n_{N_{+}}$orbitals are reduced by $>1.5 \mathrm{eV}$ on passing to the higher level theories. These changes are due to a greater effect of electron correlation and final state orbital relaxation on the $n_{N_{-}}$ 


\subsection{Mono Halogenated Pyrimidines}

When a halogen substituent is added to the aromatic ring of pyrimidine the electronic structure of the molecule changes quite significantly. First of all two new orbitals which correspond to the p orbitals of the halogen atom are added to the outer valence orbital manifold. The orientation of these orbitals can be parallel $n_{\|}$or perpendicular $n_{\perp}$ to the ring as shown in Figure 4 . In addition, the added electronegative substituent can perturb the $\pi_{3}, \pi_{2}, \pi_{1}, n_{N_{-}}$and $n_{N_{+}}$orbitals in the pyrimidine ring with respect to the parent molecule either by the inductive (I) or resonant $(\mathrm{R})$ effect. The changes in the electronic structure of the monohalogenated pyrimidines studied in this work is illustrated by a correlation diagram (see Figure 5) where the evolution of the binding energies of the various $\pi$ and $\sigma$ 
orbitals are shown at the B3LYP/6-311++G(d,p) level of theory. However, before proceeding to a detailed discussion of the interplay of the above mentioned effects we will first give a brief description of the individual PES for each molecule.

\subsubsection{2-bromopyrimidine}

The first significant change in the PES with respect to the pyrimidine parent is the shift of the lowest band to higher ionisation energy by $0.2 \mathrm{eV}$ (see Figure 6). The comparison with the $a b$ initio calculations leads to some uncertainties in the assignment of the identity of the HOMO and HOMO-1. While the B3LYP based method suggests that these orbitals are the $n_{N_{-}}$and $\pi_{3}$ orbitals, the P3 method implies that they are the $\pi_{3}$ and $n_{\|}$orbitals. This uncertainty can be resolved by examining the next band in the spectrum at $10.83 \mathrm{eV}$. This is a much sharper band with respect to the other features in the spectrum and indeed on passing to the higher resolution scan (see the upper part of Fig. 6) this band becomes narrower while the other bands do not and so appears to be limited by the resolution of the electron spectrometer. It has been noted in the literature [25] that sharp narrow bands in the PES of halogenated aromatic systems correspond to ionisation from strongly localised non-bonding orbitals as one would expect from the Franck Condon principle. In this energy region the best candidate for such an orbital is the $n_{\|}$orbital which is strongly localised on the bromine atom. In order to definitively resolve the difficulty in assigning this band, photoelectron spectra in this kinetic energy range have been recorded following ionisation of this molecule at different excitation energies using synchrotron radiation at the GasPhase photoemission beamline at Elettra. This experiment was motivated by the work of Potts et al. [9] who observed a reduction in the relative intensities of the photoelectron lines due the ionisation of bromine lone pair orbitals in the bromothiophenes at energies in the region of the Cooper minimum due to the $\mathrm{Br} 4 \mathrm{p}$ subshell around $70 \mathrm{eV}$. The comparison of the photoelectron spectra of the 2-bromopyrimidine excited following ionisation at $30 \mathrm{eV}$ and $70 \mathrm{eV}$ showed a drastic reduction ( $>$ factor of 2 ) in the relative intensity of the photoelectron line at an ionisation energy of 10.83 $\mathrm{eV}$ when the molecule is ionised with a photon energy of $70 \mathrm{eV}$. This confirms that this peak is due to ionisation of the lone pair of the $\mathrm{Br}$ atom. These results suggest that the B3LYP calculation gives the correct HOMO/HOMO-1 assignment although the ordering from an experimental point of view remains unclear. In order to test the possibility that the basis set used for the P3 calculation do not describe sufficiently the $\mathrm{Br}$ atom, the calculation has been repeated with the $6-311 \mathrm{G}(2 \mathrm{df}, 2 \mathrm{p})$ augmented by the SDD (Stuttgart/Dresden effective core potential) [26] basis set for the heavy halogen atom. The results, which are shown in Table 2 show that although the ionisation energies of the molecular orbitals with large electron density on the halogen atom do shift by a larger amount than those with little density on the halogen atom the energy ordering of the orbitals remain the same in the two calculations.

It should be noted that the largest difference between the P3/6-311G(2df,2p) and the B3LYP calculations resides in the ionisation energy, $\mathrm{E}_{i}$, of the $n_{N_{-}}$orbital $(\Delta$ $=0.91 \mathrm{eV}$ ) while the two methods give a similar result for the $\mathrm{E}_{i}$ of the $n_{\|}$orbital. Comparing to the experiment we find that both methods underestimate the $\mathrm{E}_{i}$ of the $n_{\|}$by $\sim 0.5 \mathrm{eV}$ while the P3 method overestimates the $\mathrm{E}_{i}$ of the $n_{N_{-}}$orbital and the B3LYP underestimates the same quantity. Therefore, although the B3LYP does correctly predict the $n_{\|}$to be the HOMO-2 while the P3 method does not the overall quality of the two results in comparison with the experiment are similar.

The next part of the spectrum is again quite different from the corresponding energy range of the 2-bromopyrimidine spectrum and a broad structured band 
centered at $11.89 \mathrm{eV}$ is observed. Comparison with the results of both the B3LYP and P3 calculations leads to the conclusion that the three MOs contributing to this band are the $n_{N_{+}}, \pi_{2}$ and $n_{\perp}$ orbitals, however, considering how close they are in energy to each other a definitive assignment of the energy ordering is difficult.

The absolute error of the ab initio calculations increases on going to higher binding energy orbitals. This is to be expected due to the increase of the contribution of shake-up satellite peaks and many-electron effects [4]. However, the deviations appear to be quite uniform and therefore it is still possible to at least discuss the principal contributions to these peaks. Three distinct bands are observed in the energy range from $13.5 \mathrm{eV}$ to $16.5 \mathrm{eV}$ with the intensity of the central band appearing to be larger than the other two. Both sets of calculations suggest that the first peak is due to ionisation of an inner $\sigma$ orbital, while the second contains contributions from ionisation of both the $\pi_{1}$ and $\sigma$ orbital and finally the last of these series is due to ionisation of a single $\sigma$ orbital.

\subsubsection{5-bromopyrimidine}

The lowest energy band in the PES of 5-bromopyrimidine (see Figure 7) occurs at the same energy as the corresponding band in the PES of 5-bromopyrimidine and again consists of contributions from both the HOMO and the HOMO-1. Comparison with the $a b$ initio calculations suggests that this band consists of contributions due to ionization of both the HOMO and the HOMO-1 $\left(\pi_{3}\right.$ and $n_{N_{-}}$MOs). This is in contrast to the parent pyrimidine molecule where the binding energies of these two orbitals differed by $0.8 \mathrm{eV}$. Both the P3 and the B3LYP computational methods predict a stabilisation of the $n_{N_{-}}$orbital and a destabilisation of the $\pi_{3}$ orbital. However, while the B3LYP based method predicts the ordering to be $\mathrm{BE}\left(n_{N_{-}}\right)<\mathrm{BE}\left(\pi_{3}\right)$ the $\mathrm{P} 3$ method predicts the opposite although the energy differences are small in both cases $(0.15$ and 0.21 $\mathrm{eV}$, respectively). From an experimental point of view however (even at the higher resolution scan - FWHM $\approx 75 \mathrm{meV}$ ) it is not possible to separate the two contributions but the relative intensity of the band is consistent with contributions from ionization of two MOs under this band. Again the comparison of the next highest electronic system with the $a b$ initio calculations suggest that it is the result of contributions from the ionisation of no less than three different MOs $\left(n_{\|}, n_{N_{+}}\right.$and $\left.\pi_{2}\right)$ and furthermore the two computational methods used are in agreement on the ordering of the MOs. Also in this case the experimental intensity of the band is in agreement with this conclusion. The next band (at $12.34 \mathrm{eV}$ ) is well separated and corresponds to the $n_{\perp} \mathrm{MO}$.

As in the case of the 2-bromopyrimidine the PES of 5-bromopyrimidine were recorded with photon energies of 30 and $70 \mathrm{eV}$ at the GasPhase beamline at Elettra. Comparing these spectra reveals a reduction in the relative intensity of the band at $12.34 \mathrm{eV}$ when passing from the spectra produced using photons at $30 \mathrm{eV}$ with respect to that recorded following ionisation with a photon energy of $70 \mathrm{eV}$. This is consistent with the assignment arising from the both computational methods indicating that this band is due to ionisation of the $n_{\perp} \mathrm{MO}$ which is principally located on the $\mathrm{Br}$ atom. The decrease in intensity of the central part of the band located at $11.42 \mathrm{eV}$ when comparing the PESs recorded at 30 and $70 \mathrm{eV}$ respectively suggest that the ionisation of the $n_{\|}$contributes to the central part of this band and not to the lower energy shoulder as the comparison with both computational methods would suggest.

The inner binding energy region $(13-18 \mathrm{eV})$ of the spectrum is also quite different from the corresponding region of the 2-bromopyrimidine molecule. The broad band 
between the ionisation energies 14 and $16 \mathrm{eV}$ consists of contributions from the ionisation of four MOs which are the three $\sigma$ orbitals and the most highly bound $\pi$ orbital, $\pi_{1}$. The last band in the spectrum of the 5 -bromopyrimidine appears to be less intense and broader than the corresponding feature in the 2-bromopyrimidine spectrum. Again by comparison to the calculations one can see that this is most likely due to the close matching of the ionisation energies of two $\sigma$ orbitals in the case of the 2-bromopyrimidine (see Table 2) while the corresponding orbitals in 5 -bromopyrimidine are separated by $0.25 \mathrm{eV}$ (see Table 3 ).

\subsubsection{2-chloropyrimidine}

The PES of 2-chloropyrimidine is shown in Figure 8 and the experimental band energies are compared to the $a b$ initio calculations in Table 4 . Here the P3 calculations are presented only for the cc-pVTZ and $6-311 \mathrm{G}(2 \mathrm{df}, 2 \mathrm{p})$ basis sets as the ionisation energies do not change with the SDD basis set for the lighter halogen atom chlorine. In this case on the lower energy side of the lowest energy band it is possible to see a partially resolved shoulder due to the ionisation of the HOMO. Both the P3 and B3LYP ab initio methods agree that the ordering of the HOMO and the HOMO-1 is $\mathrm{BE}\left(n_{N_{-}}\right)<\mathrm{BE}\left(\pi_{3}\right)$ although the splitting in the case of the B3LYP method $(0.29 \mathrm{eV})$ is more consistent with the observed experimental splitting than the case of the P3 calculation $(0.11 \mathrm{eV})$. The next part of the spectrum would appear to be quite similar to that of 5 -bromopyrimidine in that it consists of a broad peak with contributions from 3 MOs (partially resolved in the higher resolution scan) the identity of which are predicted by both $a b$ initio methods used here to be the $n_{\|}, n_{N_{+}}$and $\pi_{2}$ orbitals although the ordering of the latter two is unclear. Finally, a low intensity band appears at higher energy $(12.40 \mathrm{eV})$ and is due to ionisation of the $n_{\perp}$ orbital. The second half of the PES on the other hand is more similar to that of 2-bromopyrimidine and indeed the order of the MOs is predicted to be identical to that molecule by the $a b$ initio calculations.

\subsubsection{Substituent effects in the monohalogenated pyrimidines}

We begin this section with a discussion of the effects of the halogen atom on the energies of the $\pi$ orbitals. As mentioned above, the halogen atom acts on the electronic structure of the pyrimidine derivatives via two main mechanisms: the inductive effect (I) and the resonance effect (R). The energy changes induced by these effects on the $\pi$ orbitals localised on the pyrimidine ring are often antagonistic. The I effect is due to the electronegativity of the halogen substituent which withdraws electron density from the ring thus reducing the electron repulsion within the $\pi$ orbitals hence increasing their binding energies. The $\mathrm{R}$ effect, on the other hand, is due to conjugation between the lone pair orbitals of the halogen atom and the $\pi$ orbitals of the ring. The effect on the energy of the $\pi$ orbital depends on the type of conjugation. For example, in the case of the $\pi_{3}$ orbital the interaction of the electron density in the out of plane $\mathrm{p}$ orbitals of the halogen atom with the $\pi$ electrons on the pyrimidine ring leads to a nodal/anti-bonding plane along the $\mathrm{C}-\mathrm{X}$ bond. This in turn leads to a destabilisation of the $\pi_{3}$ orbital (decrease in binding energy). In order to be able to perform a quantitative discussion on the resonance effects we have performed a Mulliken population analysis on each of the Hartree-Fock MOs (see Table 5). In this table the contributions of all orbitals on each atom is summed in order to give the overall contribution of each atom to the electron density to the individual molecular orbitals.

The net effect on the $\pi_{3}$ orbitals in all of the molecules is a destabilisation with the effect being more pronounced in the case of the bromopyrimidines with respect to the chloropyrimidine (see Figure 5). As described above the I effect stabilises the $\pi_{3}$ orbital while the $\mathrm{R}$ effect destabilises it. Since the net effect is a destabilisation 
it is clear that the $\mathrm{R}$ effect dominates in this case. The relative magnitude of the destabilisation $(\mathrm{Br}>\mathrm{Cl})$ can be rationalised by an inspection of the population analysis (see Table 5) for these orbitals which shows that chlorine contributes $31.9 \%$ to the electron density of the $\pi_{3}$ orbital in 2-chloropyrimidine while $\mathrm{Br}$ contributes $47.6 \%$ and $50.1 \%$ to the corresponding orbitals in 5-bromo and 2-bromopyrimidine, respectively. This explains why the $\pi_{3}$ orbital is more destabilised in the bromine substituted molecules.

The $\pi_{2}$ orbital shows the opposite effect in that it is stabilised by the addition of the halogen atoms in all cases. This observation can again be explained by consulting the population analysis where it can be seen that the halogen atoms contribute zero to the electron density of these orbitals which means that the $\mathrm{R}$ effect has no influence on the energy of these orbitals. This is due to nodal plane perpendicular to the ring and passing through $\mathrm{C} 1$ and $\mathrm{C} 5$. Therefore, only the I effect operates in this case and as expected (due to the relative electronegativities) the effect is larger in the case of chlorine than for bromine.

The last $\pi$ orbital, $\pi_{1}$, is also stabilised but in this case both the inductive and the resonance effects stabilise the orbital as the $n_{\perp}$ conjugates in a bonding fashion with the $\pi_{1}$ orbital on the pyrimidine ring thus further stabilising this orbital.

The energy of the lone pair orbitals on the nitrogen atoms $\left(n_{N_{+}}\right.$and $\left.n_{N_{-}}\right)$are also changed by the presence of the halogen atom. Indeed, the $n_{N_{+}}$orbitals are changed in a very similar way to the $\pi_{2}$ orbitals suggesting that the principal effect operating is the inductive effect, i.e. withdrawal of electron density from the lone pair thus stabilising the $\mathrm{MO}$ and furthermore the effect is larger for chlorine than for bromine. The energy dependence of the $n_{N_{-}}$orbital is more complicated because in addition to the I effect there is a through space resonance effect between the $n_{\|}$and the antisymmetric lone pair orbitals of the nitrogen atoms resulting in further stabilisation of the $n_{N_{-}}$orbital. In the case of 5-bromopyrimidine the bromine atom is on the opposite side of the molecule with respect to the nitrogen lone pairs and thus the resonance effect is no longer possible.

The lone pairs on the halogen atoms $\left(n_{\|}\right.$and $\left.n_{\perp}\right)$ are destabilised by the inductive effect (increased electron density on the halogen atoms due to the electron withdrawing effects decreases the binding energy of these orbitals) and hence the average binding energy of these orbitals, $\left\langle\mathrm{n}>=n_{\|}+n_{\perp}\right.$, is lower than in the isolated atoms (see Figure 5). However, the resonance effects further modify the energies of these orbitals. In the case of the $n_{\perp}$ the resonance effect leads to some $\pi$ bonding character along the $\mathrm{C}-\mathrm{X}$ bond leading to a stabilisation of this orbital. In contrast, the $n_{\|}$in which the lone pair orbital lies in the plane of the pyrimidine ring interacts with the $\sigma$ orbitals of the pyrimidine ring. In all cases this leads to destabilisation of this orbital. For the 2-bromopyrimidine this effect is particularly marked due to the nodal planes which arise between the lobes of the bromine lone pair and the electron density on the nitrogen lone pairs. Indeed this effect is complementary to that described for the $n_{N_{-}}$in the previous paragraph.

\subsection{Dihalogenated Pyrimidines: 5-bromo-2-chloropyrimidine}

The He I PES of 5-bromo-2-chloropyrimidine is shown in Figure 9 while the band energies are compared to the ab initio calculation results in Table 6 . The first band (lowest ionisation energy) again consists of contribution from ionisation of both the HOMO and the HOMO-1 and the two higher level sets of $a b$ initio calculations agree that these are the $\pi_{3}$ and $n_{N_{-}}$orbitals, respectively. The second peak at $11.9 \mathrm{eV}$ consists of contributions from five different MOs among which are the $\pi_{2}$ orbital, three lone pair orbitals on the chlorine and bromine atoms and the $n_{N_{+}}$ 
orbital although the two sets of calculations predicts quite different relative energy ordering. The relative intensity of this band is in agreement with the contribution of five MOs. A small band at $13.1 \mathrm{eV}$ is due to ionisation of the $n_{\perp}(\mathrm{Br} / \mathrm{Cl})$ orbital. The more tightly bound region from $14.0-17.5 \mathrm{eV}$ contains two broad structured band, the first of which contains contributions from the ionisation of 4 MOs while the second is due to ionisation of 2 MOs. All of these MOs (apart from the $\pi_{1}$ orbital) are of $\sigma$ character.

\subsubsection{Substituent effects}

The first noticeable substituent effect is that this molecule has the lowest IP of all of the molecules examined. This is due to the change of the binding energy of the $\pi_{3}$ orbital which is destabilised by the resonance effect with the substituted halogen atoms. It appears that this effect is additive because in the 5-bromopyrimidine molecule the experimentally observed shift of this orbital with respect to the parent pyrimidine moelcule is $\Delta=-0.60 \mathrm{eV}$ while the equivalent shift in the 2chloropyrimidine molecule is $\Delta=-0.38 \mathrm{eV}$ : the sum of these value is quite close to the shift in the 5-bromo-2-chloropyrimidine molecule, i.e. $\Delta=-0.85 \mathrm{eV}$. Indeed, due to this resonance effect the $\pi_{3}$ becomes the HOMO in this molecule. The $n_{N_{-}}$orbital is stabilised by the inductive effect of the halogen atoms by 0.15 $\mathrm{eV}$ and becomes the HOMO-1. In this case it is difficult to conclude whether the effects are additive or not because the size of the shifts are comparable to the width of the peaks in the PES. However, it is consistent that the shift is very similar to the case of the 2-chloropyrimidine molecule $(\Delta=0.11 \mathrm{eV})$ as the chlorine substituent is likely to be dominant due to its proximity to the nitrogen lone pairs.

Both the $\pi_{2}$ and $n_{N_{+}}$orbitals are stabilised by the presence of the halogen atoms however as the electrons produced by the ionisation of these two MOs appear in the PES of the 5-bromo-2-chloropyrimidine molecule under a broad peak centered at $11.6 \mathrm{eV}$ it is difficult to dicuss from an experimental point of view the shifts of these orbitals with respect to the parent molecule.

The more surprising aspect of the substituent effects in the dihalogen species is the effect on the non-bonding orbitals on the halogen atoms themselves. While in the case of the mono-halogenated pyrimidines the addition of the halogen atom adds three MOs to the valence manifold (one of which lies in the inner valence shell, the other two being the $n_{\|}$and $n_{\perp}$ orbitals), the substitution with two halogen atoms leads to the addition of six new MOs inthe valence shell. By analogy to the monohalogenated species the four of these which lie in the outer valence shell would be expected to be two $n_{\|}$orbitals and two $n_{\perp}$ orbitals with one of each on the chlorine and bromine atom. This is exactly what happens for the $n_{\|}$orbitals where two quite distinct orbitals are attributable to the $n_{\|}(\mathrm{Cl})$ and the $n_{\|}(\mathrm{Br})$ orbitals. A Mulliken population analysis on the $\mathrm{HF} / 6-311++\mathrm{G}(\mathrm{d}, \mathrm{p})$ orbitals revealed that the chlorine atom contributes $38.3 \%$ to the $n_{\|}(\mathrm{Cl})$ while the bromine atoms contributes $53.9 \%$ to the $n_{\|}(\mathrm{Br})$ orbitals. The binding energies of these are predicted to be very close by the $a b$ initio calculations and on comparison with the experimental PES they are suggested to lie on the low energy side of the broad peak centered at $11.6 \mathrm{eV}$. These orbitals are close in energy in spite of the fact that the binding energy in the isolated atom is much higher for the chlorine atoms because the $n_{\|}$ $(\mathrm{Cl})$ orbital experiences additional destabilisation with respect to the $n_{\|}(\mathrm{Br})$ due to its proximity to the nitrogen lone pairs.

The situation of the $n_{\perp}$ orbitals is slightly more complicated. Upon performing a Mulliken population analysis on the first of these orbitals (lowest binding energy) it was found that it contains almost equal contributions from the chlorine $(46.2 \%)$ and bromine $(45.5 \%)$. In this orbital there is little or no binding along the $\mathrm{C}-\mathrm{X}$ bond and therefore the orbitals is not stabilised by the resonance effect and thus has a 
binding energy similar to that of the $n_{\|}$orbitals. The other $n_{\perp}$ orbital also contains comparable contributions from the chlorine $(47.0 \%)$ and bromine $(26.9 \%)$ atoms but in this case there is significant $\pi$ bonding along the $\mathrm{C}-\mathrm{X}$ bonds and indeed the energy of this orbital is strongly stabilised by the resonance effect (binding energy $=13.03 \mathrm{eV})$.

\title{
5. Conclusions
}

The valence shell photoelectron spectra of gas phase 5-bromopyrimidine, 2bromopyrimidine, 2-chloropyrimidine and 5-bromo-2-chloropyrimidine have been recorded following excitation with He I radiation. The computational methods were tested by comparison to the known assignment of the pyrimidine PES. Assignments are then proposed for all features in these PES by comparison to the vertical ionisation energies calculated by three different $a b$ initio methods and in the cases of the 2-bromopyrimidine and 5-bromopyrimidine by comparing the relative intensities of the PES recorded with photon energies of 30 and $70 \mathrm{eV}$ (the latter of which corresponds to the Cooper minimum of the Bromine atom. This experiment allowed a definitive assignment of the bands due to ionisation of molecular orbitals dominated by bromine lone pairs. Comparison of the B3LYP based method and the P3 method with these results showed similar quality results for the two methods which is surprising considering the lower level of the B3LYP calculations. It should also be noted that the remaining uncertainties in the assignments of the bands of the halogenated pyrimidines presented in this work (principally due to overlapping bands) may be resolved by future measurements on the angular distributions of the photoelectrons.

The substituent effects on the $\pi$ and $\sigma$ orbitals of the pyrimidine ring have been discussed as a function of the identity and position of the halogen atom. The shifts of the binding energies of these orbitals can be accounted for by a combination of the inductive and resonance effects of the halogen atoms of the ring orbitals.

Furthermore, the results presented in this work will provide the basis in order to permit an in depth interpretation of future experiments on the electron-ion coincidence studies on these molecules following either resonant inner shell excitation or valence shell ionisation. The fact that a knowledge of the valence shell electronic structure of a molecule is necessary to interpret electron-ion coincidence studies on that molecule is demonstated by the recent work on pyrimidine $[27,28]$.

\section{Acknowledgments}

The authors are grateful for the technical help provided by Dr. Ettore Fainelli and Marcello Mastropietro. The authors would also like to thank the High Performance Computing center at CINECA for computing time awarded via the Progetto Supercalcolo Convenzione CINECA-INFM-CNR.

\author{
References \\ [1]W.C. Dewey and R.M. Humphrey, Radiat. Res. 26, 538 (1965). \\ [2] K. Sano, T. Hoshino and M. Nagai, J. Neurosurg. 28, 530 (1968). \\ [3]L. Storchi, F. Tarantelli, S. Veronesi et al., J. Chem. Phys. 129, 154309 (2008). \\ [4] A.W. Potts, D.M.P.Holland, .A.B. Trofimov et al., Phys. Rev. B 36, 3129 (2003). \\ [5] U. Lottermoser, P. Rademacher, M. Mazik and K. Kowski, Eur. J. Org. Chem. 2005, 522 (2005). \\ [6]D.M.P. Holland, D. Edvardsson, L. Karlsson et al., Chem. Phys. 252, 257 (2000). \\ [7]D.M.P. Holland, D. Edvardsson, L. Karlsson et al., Chem. Phys. 253, 133 (2000).
}




\section{Molecular Physics}

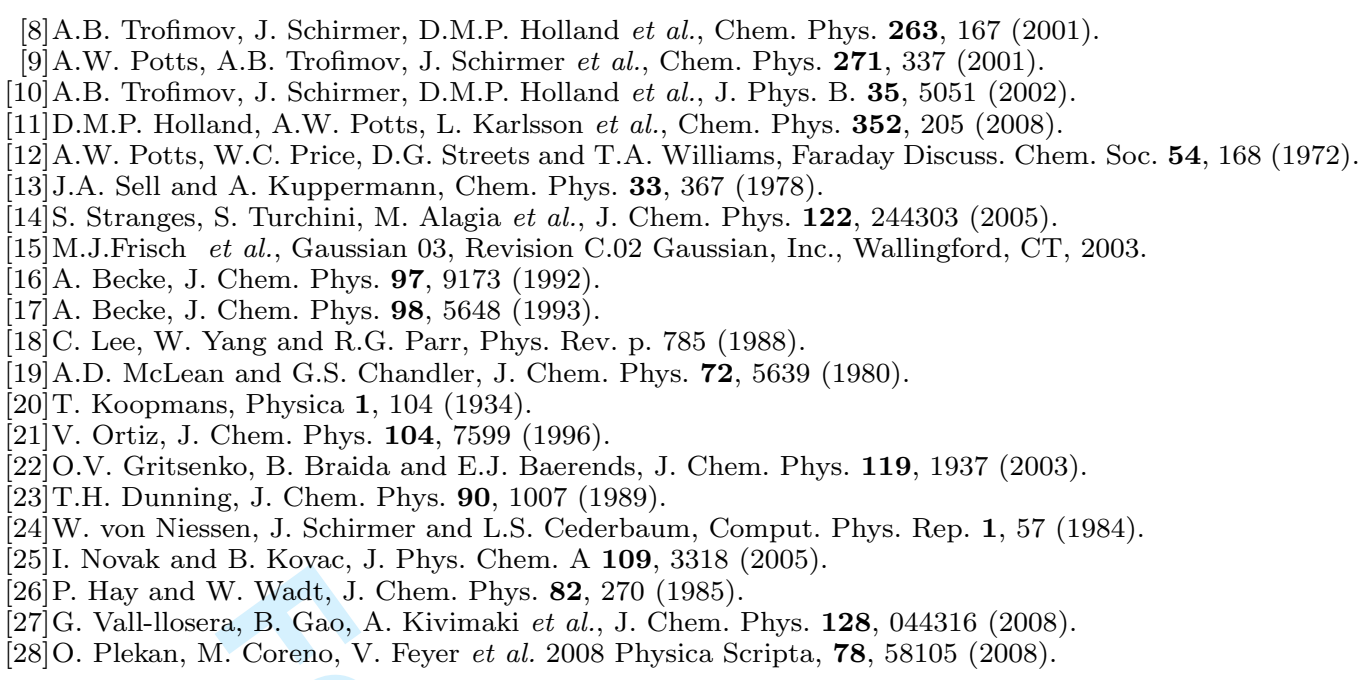




\section{Molecular Physics}<smiles>c1cncnc1</smiles><smiles>Brc1cncnc1</smiles>

pyrimidine

5-bromo

pyrimidine<smiles>Brc1ncccn1</smiles><smiles>Clc1ncccn1</smiles><smiles>Clc1ncc(Br)cn1</smiles>

2-bromo

2-chloro

5-bromo-2-chloro pyrimidine pyrimidine pyrimidine

Figure 1. Schematic representation of the pyrimidine molecule and its halogen substituted derivatives investigated in this work. Structure 1 also indicates the numbering of the ring atoms employed. 


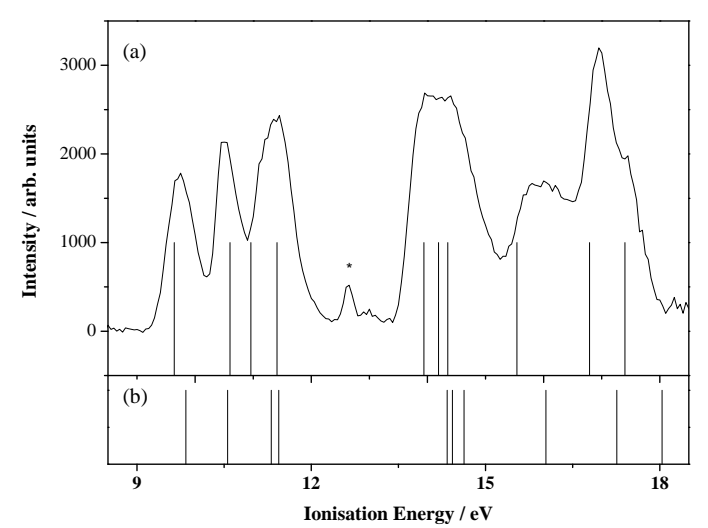

Figure 2. He I photoelectron spectrum of pyrimidine. The stick spectrum in a) indicates the ab initio ionisation energies calculated using the B3LYP method outlined in the text, while that in b) show the ionisation energies calculated using the P3/6-311G(2df,2p) method. The asterisk marks a peak due to ionisation of water molecules in the sample. 


\section{Page 15 of 42}

\section{Molecular Physics}

FIGURES

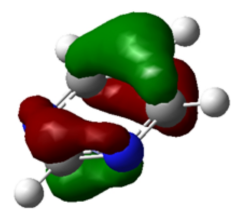

$\pi_{3}$

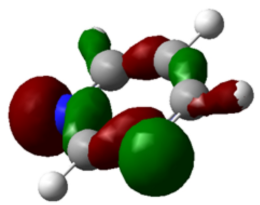

$\mathrm{n}_{\mathrm{N}}^{-}$

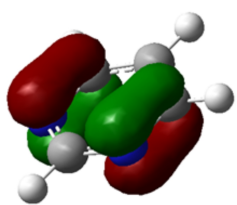

$\pi_{2}$

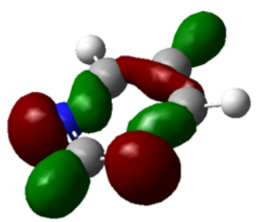

$\mathrm{n}_{\mathrm{N}}{ }^{+}$

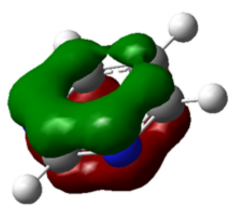

$\pi_{1}$

Figure 3. Hartree Fock molecular orbitals of pyrimidine together with the notation adopted in this work. 


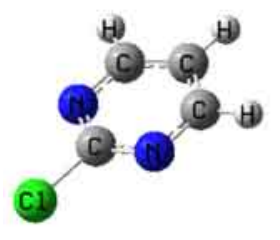

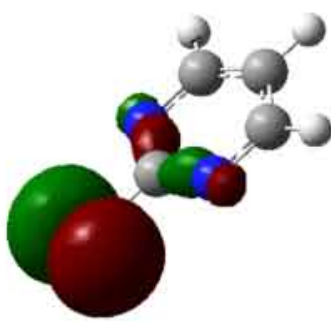

n॥

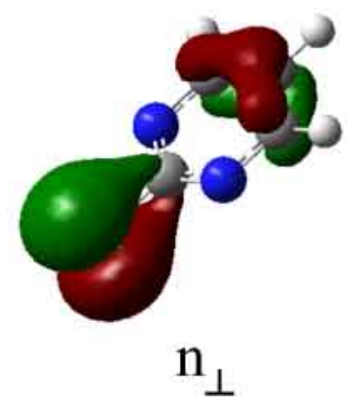

Figure 4. Hartree Fock molecular orbitals of the halogen atom lone pairs (in 2-chloropyrimidine) together with the notation adopted in this work. 


\section{Page 17 of 42}

16

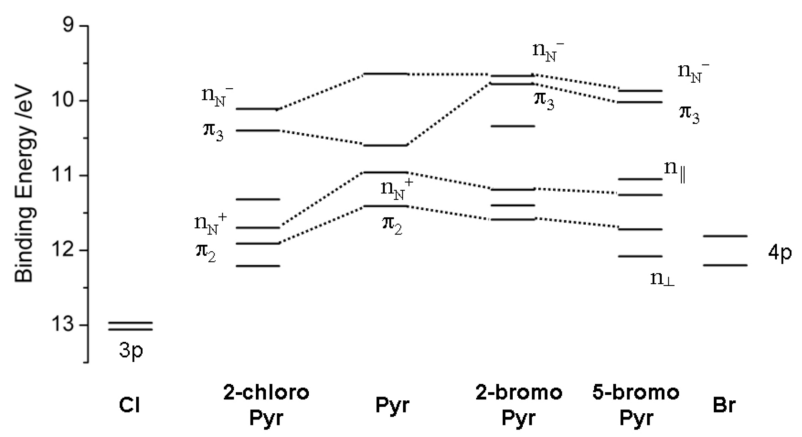

Figure 5. Correlation diagram for the halogenated pyrimidines as calculated using the B3LYP method (see text for details).

\section{Molecular Physics}

FIGURES
1

4

5

6

8

9

10

12

13

14

15

16

17

18

19

20

21

22

23

24

25

26

27

28

29

30

31

32

33

34

35

36

37

38

39

40

41

42

43

44

45

46

47

48

49

50

51

52

53

54

55

56

57

58

59

60 
Figure 6. He I photoelectron spectrum of 2-bromopyrimidine. The stick spectrum in a) indicates the $a b$ initio ionisation energies calculated using the B3LYP method outlined in the text, while that in b) show the ionisation energies calculated using the P3/6-311G(2df,2p)/SDD method. The inset represents a high resolution scan of the ionisation energy region $9-12.5 \mathrm{eV}$. 


\section{Molecular Physics}

18

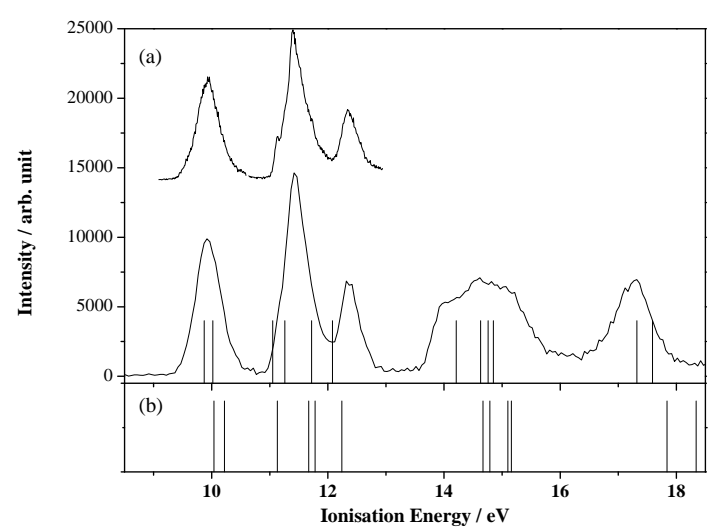

Figure 7. He I photoelectron spectrum of 5-bromopyrimidine. The stick spectrum in a) indicates the $a b$ initio ionisation energies calculated using the B3LYP method outlined in the text, while that in b) is due to the P3/6-311G(2df,2p)/SDD method. The inset represents a high resolution scan of the ionisation energy region $9-13 \mathrm{eV}$.

3

6

8

10

11

14

15

16

19

20

21

22

23

24

25

26

27

28

29

30

31

32

33

34

35

36

37

41

42

43

44

45

46

47

48

49

50

51

52

53

54

55

56

57

58

59

60 
Figure 8. He I photoelectron spectrum of 2-chloropyrimidine. The stick spectrum in a) indicates the $a b$ initio ionisation energies calculated using the B3LYP method outlined in the text, while that in b) show the ionisation energies calculated using the P3/6-311G(2df,2p) method. The inset represents a high resolution scan of the ionisation energy region $9-13 \mathrm{eV}$. 


\section{Molecular Physics}

20

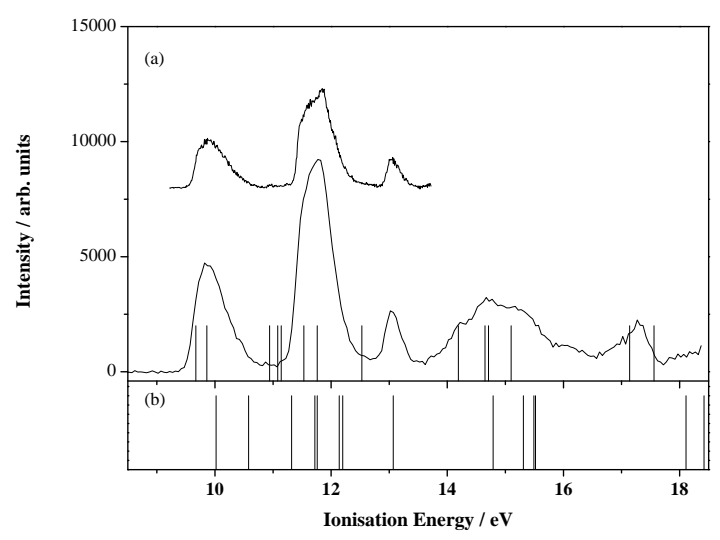

Figure 9. He I photoelectron spectrum of 5-bromo-2-chloropyrimidine. The stick spectrum in a) indicates the $a b$ initio ionisation energies calculated using the B3LYP method outlined in the text, while that in b) show the ionisation energies calculated using the P3/6-311G(2df,2p)/SDD method . The inset represents a high resolution scan of the ionisation energy region $9-14 \mathrm{eV}$.

1

4

5

6
7

8

10

11

13

14

15

17

18

19

20

21

22

23

24

25

26

27

28

29

30

31

32

33

34

35

36

37

38

40

41

42

43

44

45

46

47

48

49

50

51

52

53

54

55

56

57

58

59

60 


\section{Molecular Physics}

TABLES

\begin{tabular}{|l|c|c|c|c|c|c|}
\hline Exp. & Orb. & MO & $\begin{array}{c}\text { HF } \\
\text { cc-pVTZ }\end{array}$ & $\begin{array}{c}\text { P3(PS) } \\
\text { cc-pVTZ }\end{array}$ & $\begin{array}{c}\text { P3 } \\
6-311 \mathrm{G}(2 \mathrm{df}, 2 \mathrm{p})\end{array}$ & B3LYP \\
\hline 9.73 & $5 b_{2}$ & $n_{N_{-}}$ & 11.29 & $9.90(0.89)$ & 9.84 & 9.64 \\
10.53 & $2 b_{1}$ & $\pi_{3}$ & 10.26 & $10.60(0.89)$ & 10.56 & 10.59 \\
$11.20 \mathrm{sh}$ & $7 a_{1}$ & $n_{N_{+}}$ & 12.88 & $11.37(0.88)$ & 11.31 & 10.96 \\
11.40 & $1 a_{2}$ & $\pi_{2}$ & 11.48 & $11.48(0.88)$ & 11.44 & 11.40 \\
13.95 & $1 b_{1}$ & $\pi_{1}$ & 15.68 & $14.38(0.81)$ & 14.34 & 13.94 \\
& $6 a_{1}$ & $\sigma$ & 15.95 & $14.49(0.87)$ & 14.43 & 14.18 \\
14.40 & $5 a_{1}$ & $\sigma$ & 16.19 & $14.69(0.88)$ & 14.63 & 14.35 \\
15.95 & $3 b_{2}$ & $\sigma$ & 17.71 & $16.10(0.86)$ & 16.04 & 15.52 \\
16.95 & $4 a_{1}$ & $\sigma$ & 19.07 & $17.31(0.85)$ & 17.26 & 16.78 \\
17.45 & $3 a_{1}$ & $\sigma$ & 20.09 & $18.10(0.84)$ & 18.06 & 17.38 \\
\hline
\end{tabular}

Table 1. Experimental band energies taken from the He I PES of pyrimidine together with the assignments of each band. sh indicates a shoulder in experimental spectrum. Also shown are the calculated ionisation energies obtained using the three computational methods outlined in the text. The results of the HF and P3 calculations are reported for two different basis sets: cc-pVTZ and 6-311G(2df,2p). The pole strengths of the P3 calculations are presented in brackets after P3 ionisation energies for the cc-pVTZ basis set. All energies are in eV. 


\section{Page 23 of 42}

\section{Molecular Physics}

TABLES
1

2

3

4

5

7

8

9

10

11

12

13

14

15

16

17

18

19

20

21

22

23

24

25

26

27

28

29

30

31

32

33

34

35

36

37

38

39

40

41

42

43

44

45

46

47

48

49

50

51

52

53

54

55

56

57

58

59

60

\begin{tabular}{|l|c|c|c|c|c|c|c|}
\hline Orbital & MO & Exp. & $\begin{array}{c}\text { HF } \\
\text { cc-pVTZ }\end{array}$ & $\begin{array}{c}\text { P3 (PS) } \\
\text { cc-pVTZ }\end{array}$ & $\begin{array}{c}\text { P3 } \\
6-311 \mathrm{G}(2 \mathrm{df}, 2 \mathrm{p})\end{array}$ & $\begin{array}{c}\text { P3 } \\
\text { 6-311G(2df,2p) } \\
\text { SDD }\end{array}$ & B3LYP \\
\hline $5 b_{2}$ & $n_{N_{-}}$ & 9.93 & 11.97 & $10.61(0.88)$ & 10.56 & 10.58 & 9.67 \\
$3 b_{1}$ & $\pi_{3}$ & & 10.12 & $10.09(0.89)$ & 10.05 & 10.08 & 9.78 \\
$6 b_{2}$ & $n_{\|}$ & 10.83 & 11.19 & $10.27(0.90)$ & 10.19 & 10.27 & 10.34 \\
$8 a_{1}$ & $n_{N_{+}}$ & $11.24 \mathrm{sh}$ & 12.97 & $11.76(0.88)$ & 11.70 & 11.73 & 11.19 \\
$2 b_{1}$ & $n_{\perp}$ & 11.63 & 12.16 & $11.65(0.89)$ & 11.59 & 11.66 & 11.40 \\
$1 a_{2}$ & $\pi_{2}$ & 11.89 & 11.99 & $11.85(0.87)$ & 11.81 & 11.81 & 11.59 \\
$7 a_{1}$ & $\sigma$ & 13.73 & 15.49 & $14.10(0.87)$ & 14.05 & 14.08 & 13.67 \\
$4 b_{2}$ & $\sigma$ & 14.48 & 16.66 & $15.04(0.87)$ & 15.00 & 15.00 & 14.34 \\
$1 b_{1}$ & $\pi_{1}$ & & 16.52 & $15.03(0.80)$ & 15.00 & 15.00 & 14.78 \\
$6 a_{1}$ & $\sigma$ & 15.58 & 19.74 & $16.01(0.86)$ & 15.96 & 15.97 & 15.26 \\
$3 b_{2}$ & $\sigma$ & 17.08 & 17.62 & $17.84(0.84)$ & 17.80 & 17.80 & 17.11 \\
$5 a_{1}$ & $\sigma$ & & 19.85 & $17.88(0.84)$ & 17.83 & 17.84 & 17.12 \\
\hline
\end{tabular}

Table 2. Experimental band energies derived from the He I PES of 2-bromopyrimidine together with the assignments of each band. sh indicates a shoulder in the experimental spectrum. Also shown are the calculated

ionisation energies obtained using the three computational methods outlined in the text. All energies are in eV. 


\section{Molecular Physics}

Page 24 of 42

TABLES

\begin{tabular}{|l|c|c|c|c|c|c|c|}
\hline Orbital & MO & Exp. & $\begin{array}{c}\text { HF } \\
\text { cc-pVTZ }\end{array}$ & $\begin{array}{c}\text { P3 (PS) } \\
\text { cc-pVTZ }\end{array}$ & $\begin{array}{c}\text { P3 } \\
6-311 \mathrm{G}(2 \mathrm{df}, 2 \mathrm{p})\end{array}$ & $\begin{array}{c}\text { P3 } \\
6-311 \mathrm{G}(2 \mathrm{df}, 2 \mathrm{p}) \\
\text { SDD }\end{array}$ & B3LYP \\
\hline $6 b_{2}$ & $n_{N_{-}}$ & 9.93 & 11.45 & $10.26(0.89)$ & 10.19 & 10.22 & 9.87 \\
$3 b_{1}$ & $\pi_{3}$ & & 9.97 & $10.05(0.89)$ & 10.00 & 10.04 & 10.02 \\
$5 b_{2}$ & $n_{\|}$ & $11.13 \mathrm{sh}$ & 12.19 & $11.12(0.89)$ & 11.06 & 11.13 & 11.05 \\
$8 a_{1}$ & $n_{N_{+}}$ & 11.42 & 13.05 & $11.71(0.88)$ & 11.65 & 11.67 & 11.27 \\
$1 a_{2}$ & $\pi_{2}$ & 11.42 & 11.92 & $11.81(0.87)$ & 11.78 & 11.78 & 11.72 \\
$2 b_{1}$ & $n_{\perp}$ & 12.34 & 12.90 & $12.24(0.88)$ & 12.18 & 12.24 & 12.09 \\
$7 a_{1}$ & $\sigma$ & $14.02 \mathrm{sh}$ & 16.10 & $14.70(0.86)$ & 14.63 & 14.67 & 14.21 \\
$4 b_{2}$ & $\sigma$ & 14.60 & 16.51 & $15.14(0.87)$ & 15.16 & 15.16 & 14.63 \\
$1 b_{1}$ & $\pi_{1}$ & $15.22 \mathrm{sh}$ & 16.28 & $14.82(0.80)$ & 14.79 & 14.79 & 14.77 \\
$6 a_{1}$ & $\sigma$ & & 16.79 & $15.20(0.87)$ & 15.10 & 15.10 & 14.86 \\
$3 b_{2}$ & $\sigma$ & $17.1 \mathrm{sh}$ & 19.77 & $17.88(0.84)$ & 17.84 & 17.84 & 17.32 \\
$5 a_{1}$ & $\sigma$ & 17.3 & 20.42 & $18.38(0.84)$ & 18.33 & 18.34 & 17.58 \\
\hline
\end{tabular}

Table 3. Experimental band energies derived from the He I PES of 5-bromopyrimidine together with the asionisation energies obtained using the three computational methods outlined in the text. All energies are in $\mathrm{eV}$. 
TABLES

\begin{tabular}{|l|c|c|c|c|c|c|}
\hline Orbital & MO & Exp. & $\begin{array}{c}\text { HF } \\
\text { cc-pVTZ }\end{array}$ & $\begin{array}{c}\text { P3 (PS) } \\
\text { cc-pVTZ }\end{array}$ & $\begin{array}{c}\text { P3 } \\
6-311 \mathrm{G}(2 \mathrm{df}, 2 \mathrm{p})\end{array}$ & B3LYP \\
\hline $6 b_{2}$ & $n_{N_{-}}$ & 9.84 & 11.77 & $10.26(0.88)$ & 10.22 & 10.11 \\
$3 b_{1}$ & $\pi_{3}$ & 10.15 & 10.28 & $10.37(0.89)$ & 10.40 & 10.40 \\
$5 b_{2}$ & $n_{\|}$ & 11.38 & 12.62 & $11.55(0.89)$ & 11.54 & 11.32 \\
$8 a_{1}$ & $n_{N_{+}}$ & 11.61 & 13.41 & $11.94(0.88)$ & 11.90 & 11.69 \\
$1 a_{2}$ & $\pi_{2}$ & 11.80 & 11.99 & $11.86(0.87)$ & 11.84 & 11.90 \\
$2 b_{1}$ & $n_{\perp}$ & 12.40 & 13.15 & $12.29(0.88)$ & 12.27 & 12.21 \\
$7 a_{1}$ & $\sigma$ & $14.2 \mathrm{sh}$ & 16.02 & $14.68(0.87)$ & 14.66 & 14.40 \\
$4 b_{2}$ & $\sigma$ & 14.5 & 16.66 & $15.07(0.87)$ & 15.04 & 14.66 \\
$1 b_{1}$ & $\pi_{1}$ & $14.9 \mathrm{sh}$ & 16.65 & $15.17(0.81)$ & 15.16 & 15.20 \\
$6 a_{1}$ & $\sigma$ & 15.8 & 17.75 & $16.16(0.86)$ & 16.13 & 15.74 \\
$3 b_{2}$ & $\sigma$ & 17.3 & 19.78 & $17.91(0.85)$ & 17.88 & 17.47 \\
$5 a_{1}$ & $\sigma$ & & 19.94 & $17.99(0.84)$ & 17.97 & 17.51 \\
\hline
\end{tabular}

Table 4. Experimental band energies derived from the He I PES of 2-chloropyrimidine together with the as-
signments of each band. sh indicates a shoulder in the experimental spectrum. Also shown are the calculated ionisation energies obtained using the three computational methods outlined in the text. All energies are in eV. 


\begin{tabular}{|l|r|r|r|r|r|r|}
\hline & $\pi_{3}$ & $n_{N_{-}}$ & $\pi_{2}$ & $n_{N_{+}}$ & $n_{\|}$ & $n_{\perp}$ \\
\hline Pyrimidine & & & & & & \\
C2 & 7.7 & 33.4 & 32.9 & 28.8 & & \\
N3 & 22.2 & 5.2 & 0.4 & 8.2 & & \\
C4 & 7.7 & 33.4 & 32.9 & 28.8 & & \\
C5 & 9.7 & 8.1 & 16.9 & 6.9 & & \\
C6 & 42.9 & 7.1 & 0.1 & 13.4 & & \\
& 9.7 & 8.4 & 16.9 & 6.9 & & \\
\hline 5-bromopyrimidine & & & & & & \\
N1 & 3.2 & 13.4 & 32.4 & 25.7 & 11.8 & 3.9 \\
C2 & 11.4 & 1.8 & 0.4 & 7.9 & 2.1 & 6.6 \\
N3 & 3.2 & 13.4 & 32.4 & 25.7 & 11.8 & 3.9 \\
C4 & 6.4 & 17.8 & 17.3 & 5.6 & 7.3 & 0.4 \\
C5 & 21.9 & 7.9 & 0.1 & 11.2 & 5.3 & 11.0 \\
C6 & 6.4 & 17.8 & 17.3 & 5.6 & 7.3 & 0.4 \\
Br & 47.6 & 26.3 & 0.0 & 14.4 & 52.7 & 73.9 \\
& & & & & & \\
\hline 2-bromopyrimidine & & & & & & \\
N1 & 6.0 & 27.6 & 33.7 & 20.7 & 10.8 & 0.1 \\
C2 & 9.7 & 7.4 & 0.4 & 14.7 & 1.7 & 6.3 \\
N3 & 6.0 & 27.6 & 33.7 & 20.7 & 10.8 & 0.1 \\
C4 & 3.6 & 6.5 & 16.0 & 5.5 & 5.0 & 5.1 \\
C5 & 21.0 & 5.7 & 0.1 & 12.3 & 1.4 & 12.6 \\
C6 & 3.6 & 6.5 & 16.0 & 5.5 & 5.0 & 5.1 \\
Br & 50.1 & 14.1 & 0.0 & 18.7 & 64.6 & 70.7 \\
& & & & & & \\
\hline 2-chloropyrimidine & & & & & & \\
N1 & 7.1 & 29.0 & 33.8 & 24.0 & 11.4 & 0.5 \\
C2 & 14.0 & 4.1 & 0.5 & 11.6 & 10.6 & 2.0 \\
N3 & 7.1 & 29.0 & 33.8 & 24.0 & 11.4 & 0.5 \\
C4 & 5.5 & 9.7 & 15.9 & 5.7 & 2.6 & 3.7 \\
C5 & 28.9 & 5.5 & 0.1 & 15.4 & 1.8 & 6.7 \\
C6 & 5.5 & 9.7 & 15.9 & 5.7 & 2.6 & 3.7 \\
Cl & 31.9 & 9.6 & 0.0 & 11.0 & 58.7 & 82.9 \\
\hline
\end{tabular}

Table 5. Mulliken population analysis on the MOs of pyrimidine, 5-bromopyrimidine, 2-bromopyrimidine and 2-chloropyrimidine (sum of contributions of all AOs belonging to the same atom to the electron density of a given MO expressed as a percentage of the total electron density on that MO). 


\section{Page 27 of 42}

\section{Molecular Physics}

TABLES
1

2

3

4

5

6

7

8

9

10

11

12

13

14

15

16

17

18

19

20

21

22

23

24

25

26

27

28

29

30

31

32

33

34

35

36

37

38

39

40

41

42

43

44

45

46

47

48

49

50

51

52

53

54

55

56

57

58

59

60

\begin{tabular}{|c|c|c|c|c|c|c|c|}
\hline Orbital & $\mathrm{MO}$ & Exp. & $\begin{array}{c}\text { HF } \\
\text { cc-pVTZ }\end{array}$ & $\begin{array}{l}\text { P3 (PS) } \\
\text { cc-pVTZ }\end{array}$ & $\begin{array}{c}\mathrm{P} 3 \\
6-311 \mathrm{G}(2 \mathrm{df}, 2 \mathrm{p})\end{array}$ & $\begin{array}{c}\mathrm{P} 3 \\
6-311 \mathrm{G}(2 \mathrm{df}, 2 \mathrm{p}) \\
\text { SDD }\end{array}$ & B3LYP \\
\hline $4 b_{1}$ & $\pi_{3}$ & 9.68 & 10.04 & $10.01(0.89)$ & 9.99 & 10.02 & 9.66 \\
\hline $7 b_{2}$ & $n_{N_{-}}$ & 9.88 & 11.75 & $10.58(0.89)$ & 10.54 & 10.58 & 9.85 \\
\hline $6 b_{2}$ & $n_{\|}(\mathrm{Br})$ & $11.47 \mathrm{sh}$ & 12.49 & $11.31(0.89)$ & 11.23 & 11.32 & 10.93 \\
\hline $5 b_{2}$ & $n_{\|}(\mathrm{Cl})$ & & 12.90 & $11.76(0.89)$ & 11.76 & 11.76 & 11.06 \\
\hline $3 b_{1}$ & $n_{\perp}(\mathrm{Br} / \mathrm{Cl})$ & 11.6 & 12.57 & $11.71(0.89)$ & 11.67 & 11.72 & 11.12 \\
\hline $9 a_{1}$ & $n_{N_{+}}$ & & 13.53 & $12.22(0.88)$ & 12.18 & 12.20 & 11.52 \\
\hline $1 a_{2}$ & $\pi_{2}$ & 11.85 & 12.39 & $12.16(0.86)$ & 12.14 & 12.14 & 11.75 \\
\hline $2 b_{1}$ & $n_{\perp}(\mathrm{Br} / \mathrm{Cl})$ & 13.03 & 13.95 & $13.07(0.88)$ & 13.05 & 13.07 & 12.52 \\
\hline $8 a_{1}$ & $\sigma$ & 14.20 & 16.49 & $14.81(0.86)$ & 15.28 & 15.31 & 14.18 \\
\hline $4 b_{2}$ & $\sigma$ & 14.64 & 17.21 & $15.54(0.87)$ & 15.52 & 15.52 & 14.64 \\
\hline $7 a_{1}$ & $\sigma$ & & 16.28 & $15.30(0.87)$ & 14.78 & 14.79 & 14.70 \\
\hline $1 b_{1}$ & $\pi_{1}$ & 15.25 & 17.12 & $15.50(0.80)$ & 15.49 & 15.49 & 15.09 \\
\hline $6 a_{1}$ & $\sigma$ & 17.28 & 20.01 & $18.14(0.84)$ & 18.11 & 18.11 & 17.13 \\
\hline $3 b_{2}$ & $\sigma$ & & 20.43 & $18.44(0.84)$ & 18.42 & 18.42 & 17.55 \\
\hline
\end{tabular}

Table 6. Experimental band energies derived from the He I PES of 5-bromo-2-chloropyrimidine together with the assignments of each band. Also shown are the calculated ionisation energies obtained using the three computational methods outlined in the text. All energies are in $\mathrm{eV}$. 


\section{Supporting Information for \\ "An Experimental and Computational Study of the Valence Photoelectron Spectra of Halogenated Pyrimidines"}

Patrick O'Keeffe, Paola Bolognesi, Anna Rita Casavola, Daniele Catone, Nicola Zema, Stefano Turchini and Lorenzo Avaldi.

\section{Pyrimidine:}

\subsection{Geometry}

optimised Z-matrix at the b31yp/6-311++g $(d, p)$ level of theory

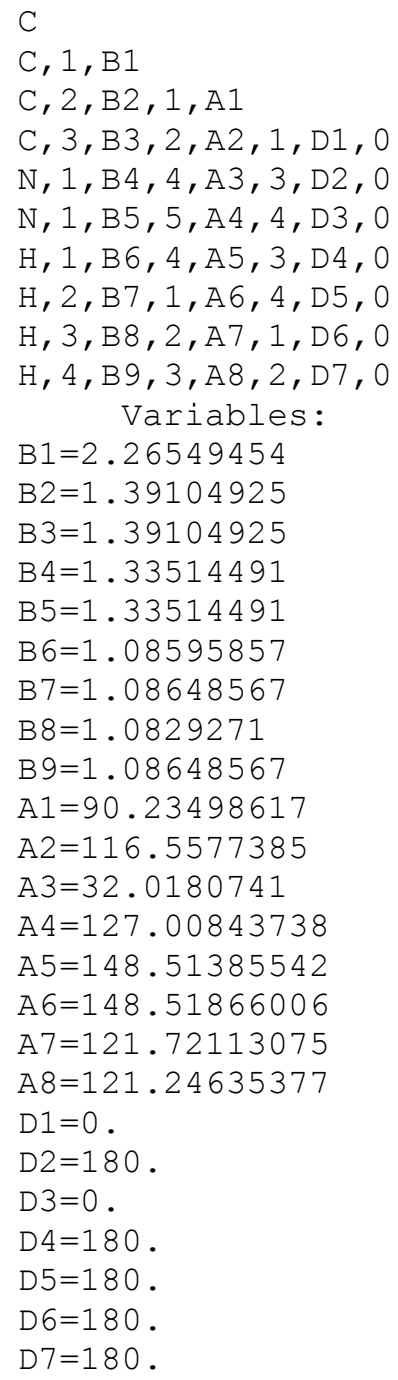

\subsection{Total Energy}


$\mathrm{E}(\mathrm{RB}+\mathrm{HF}-\mathrm{LYP})=-264.393935420$ Hartrees

\subsection{Frequencies}

Output from the "b3lyp/6-311++g(d,p) freq" calculation

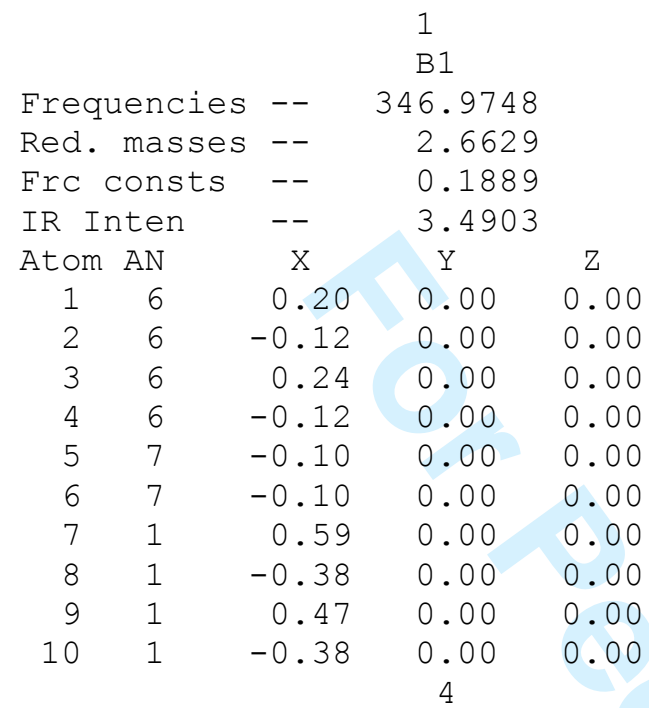

A1

Frequencies
Red. masses
Frc consts
IR Inten
Atom AN

1
2

$\begin{array}{ll}2 & 6 \\ 3 & 6\end{array}$

46

5

67

71

81

$\begin{array}{rr}9 & 1 \\ 10 & 1\end{array}$

$$
101
$$

0.00

696

7.3288

2.0918

3.0989

$$
\mathrm{Y}
$$

0.00

0.00

0.00

0.00

0.00

0.00

0.00

0.00

0.00

0.00

$-0.26$

0.00

0.26

0.26

$-0.26$

0.00

$-0.12$

0.00

0.1$$
\text { B1 }
$$

Frequencies --

Red. masses --

Frc consts --

IR Inten

Atom AN

$$
\begin{array}{rrr}
1 & 6 & -0.12 \\
2 & 6 & -0.05 \\
3 & 6 & 0.11 \\
4 & 6 & -0.05 \\
5 & 7 & 0.02 \\
6 & 7 & 0.02 \\
7 & 1 & 0.67 \\
8 & 1 & 0.28 \\
9 & 1 & -0.60 \\
10 & 1 & 0.28
\end{array}
$$

975.

$$
1.3674
$$

0.7673

0.0274

$$
\mathrm{Y}
$$

0.00

0.00

0.00

0.00

0.00

0.00

0.00

0.00

0.00

0.00

10

A1

Frequencies -- 1011.1710

Red. masses --

9.8208

5.9163

0.00

Frc consts

$\begin{array}{ccc} & 2 \\ & \text { A2 } & \\ & 406.8478 \\ & 4.1300 \\ & 0.4028 \\ & & \\ & 0.0000 & \\ X & Y & Z \\ 0.00 & 0.00 & 0.00 \\ 0.23 & 0.00 & 0.00 \\ 0.00 & 0.00 & 0.00 \\ -0.23 & 0.00 & 0.00 \\ 0.27 & 0.00 & 0.00 \\ -0.27 & 0.00 & 0.00 \\ 0.00 & 0.00 & 0.00 \\ 0.61 & 0.00 & 0.00 \\ 0.00 & 0.00 & 0.00 \\ -0.61 & 0.00 & 0.00 \\ & 5 & \end{array}$

B1

$-0.34$

0.02

0.40

0.02

$-0.02$

$-0.02$

$-0.35$

$-0.26$

0.40

$-0.26$

Z

0.00

0.00

0.00

0.00

0.00

0.00

0.00

0.00

0.00
732.9806

1.7381

0.5502

43.7288

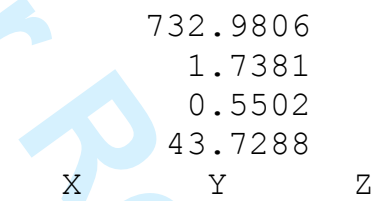

$-0.07$

0.14

$-0.07$

0.11

0.11

$-0.52$

$-0.31$

$-0.52$

0.00

0.00

0.00

0.00

0.00

0.00

0.00

0.00

0.00

8

A2

993.2509

1.3792

0.8017

0.0000

$\mathrm{X}$
0.00

$-0.13$

0.00

0.13

$-0.02$

0.02

0.00

0.70

0.00

$-0.70$

$\mathrm{Y}$

0.00

0.00

0.00

0.00

0.00

0.00

0.00

0.00

0.00

0.00

11

A 1

1079.5348

3.5422

2.4322 $\begin{array}{lll}-0.10 & 0.00 & 0.00\end{array}$

$-0.55$
3

636.1803

7.9786

1.9025

9.9897

$\begin{array}{lll}X & Y\end{array}$

$\begin{array}{lll}0.00 & -0.14 & 0.00\end{array}$

$\begin{array}{lll}0.00 & 0.26 & 0.23\end{array}$

$\begin{array}{lll}0.00 & 0.21 & 0.00\end{array}$

$\begin{array}{llll}0.00 & 0.26 & -0.23\end{array}$

$0.00 \quad-0.28 \quad-0.25$

$\begin{array}{lll}0.00 & -0.28 & 0.25\end{array}$

$\begin{array}{lll}0.00 & 0.20 \quad 0.00\end{array}$

$\begin{array}{lll}0.00 & 0.40 & -0.03\end{array}$

$\begin{array}{lll}0.00 & -0.25 & 0.00\end{array}$

$0.00 \quad 0.40 \quad 0.03$

6

B1

820.9289

1.7356

0.6891

6.8741

$\begin{array}{lll}X & Y\end{array}$

$\begin{array}{lll}0.09 & 0.00 \quad 0.00\end{array}$

$\begin{array}{lll}0.13 & 0.00 & 0.00\end{array}$

$\begin{array}{lll}0.01 & 0.00 & 0.00\end{array}$

$0.13 \quad 0.00 \quad 0.00$

$\begin{array}{lll}-0.10 & 0.00 & 0.00\end{array}$

$\begin{array}{lll}-0.10 & 0.00 & 0.00\end{array}$

$\begin{array}{lll}-0.02 & 0.00 & 0.00\end{array}$

$\begin{array}{lll}-0.31 & 0.00 & 0.00\end{array}$

$\begin{array}{lll}-0.87 & 0.00 & 0.00\end{array}$

$-0.31$

0.00

0.00

B1

1010.7519

1.4915

0.8978

0.0024

$\begin{array}{lll} & .0024 \\ - & Y\end{array}$

$\begin{array}{lll}-0.15 & 0.00 & 0.00\end{array}$

$\begin{array}{lll}0.08 & 0.00 & 0.00\end{array}$

$\begin{array}{lll}-0.08 & 0.00 & 0.00\end{array}$

$\begin{array}{lll}0.08 & 0.00 & 0.00\end{array}$

$\begin{array}{lll}0.02 & 0.00 & 0.00\end{array}$

$\begin{array}{lll}0.02 & 0.00 & 0.00\end{array}$

$\begin{array}{lll}0.64 & 0.00 & 0.00\end{array}$

$\begin{array}{rrr}-0.47 & 0.00 & 0.00\end{array}$

$\begin{array}{lll}0.33 & 0.00 & 0.00\end{array}$

$\begin{array}{lll}-0.47 & 0.00 & 0.00\end{array}$

12

B2

1093.8032

1.5209

1.0721 


\begin{tabular}{|c|c|c|c|c|c|c|c|c|c|c|}
\hline \multicolumn{2}{|c|}{ IR Inten } & -- & \multicolumn{2}{|c|}{3.5487} & \multicolumn{3}{|c|}{1.0178} & \multicolumn{3}{|c|}{3.8101} \\
\hline Atom & AN & X & $\mathrm{Y}$ & Z & $\mathrm{X}$ & $Y$ & Z & $\mathrm{X}$ & Y & Z \\
\hline 1 & 6 & 0.00 & 0.00 & 0.08 & 0.00 & 0.00 & -0.15 & 0.00 & 0.08 & 0.00 \\
\hline 2 & 6 & 0.00 & 0.00 & -0.05 & 0.00 & 0.30 & 0.07 & 0.00 & -0.08 & -0.04 \\
\hline 3 & 6 & 0.00 & 0.00 & -0.49 & 0.00 & 0.00 & 0.09 & 0.00 & 0.09 & 0.00 \\
\hline 4 & 6 & 0.00 & 0.00 & -0.05 & 0.00 & -0.30 & 0.07 & 0.00 & -0.08 & 0.04 \\
\hline 5 & 7 & 0.00 & 0.42 & 0.24 & 0.00 & 0.07 & -0.01 & 0.00 & -0.04 & -0.07 \\
\hline 6 & 7 & 0.00 & -0.42 & 0.24 & 0.00 & -0.07 & -0.01 & 0.00 & -0.04 & 0.07 \\
\hline 7 & 1 & 0.00 & 0.00 & 0.08 & 0.00 & 0.00 & -0.16 & 0.00 & 0.31 & 0.00 \\
\hline 8 & 1 & 0.00 & -0.01 & -0.06 & 0.00 & 0.51 & -0.32 & 0.00 & -0.10 & 0.00 \\
\hline 9 & 1 & 0.00 & 0.00 & -0.52 & 0.00 & 0.00 & 0.12 & 0.00 & 0.92 & 0.00 \\
\hline 10 & 1 & 0.00 & 0.01 & -0.06 & 0.00 & -0.51 & -0.32 & 0.00 & -0.10 & 0.00 \\
\hline & & & 13 & & & 14 & & & 15 & \\
\hline & & & A1 & & & B2 & & & B2 & \\
\hline Frequ & lencies & -- & 1160.504 & & & 214.60 & & & 252.953 & \\
\hline Red. & masses & -- & 2.537 & & & 3.86 & & & 1.753 & \\
\hline Frc o & zonsts & -- & 2.013 & & & 3.35 & & & 1.621 & \\
\hline IR In & ten & -- & $0.90<$ & & & 4.70 & & & 9.773 & \\
\hline Atom & AN & X & Y & Z & $X$ & $\mathrm{Y}$ & Z & $X$ & $\mathrm{Y}$ & Z \\
\hline 1 & 6 & 0.00 & 0.00 & 0.29 & 0.00 & 0.12 & 0.00 & 0.00 & 0.21 & 0.00 \\
\hline 2 & 6 & 0.00 & -0.01 & -0.13 & 0.00 & -0.05 & 0.24 & 0.00 & -0.05 & 0.00 \\
\hline 3 & 6 & 0.00 & 0.00 & 0.12 & 0.00 & 0.16 & 0.00 & 0.00 & 0.04 & 0.00 \\
\hline 4 & 6 & 0.00 & 0.01 & -0.13 & 0.00 & -0.05 & -0.24 & 0.00 & -0.05 & 0.00 \\
\hline 5 & 7 & 0.00 & 0.05 & -0.04 & 0.00 & -0.06 & 0.19 & 0.00 & -0.07 & 0.05 \\
\hline 6 & 7 & 0.00 & -0.05 & -0.04 & 0.00 & -0.06 & -0.19 & 0.00 & -0.07 & -0.05 \\
\hline 7 & 1 & 0.00 & 0.00 & 0.30 & 0.00 & -0.46 & 0.00 & 0.00 & 0.45 & 0.00 \\
\hline 8 & 1 & 0.00 & 0.21 & -0.58 & 0.00 & -0.17 & 0.44 & 0.00 & 0.18 & -0.48 \\
\hline 9 & 1 & 0.00 & 0.00 & 0.13 & 0.00 & 0.31 & 0.00 & 0.00 & -0.45 & 0.00 \\
\hline 10 & 1 & 0.00 & -0.21 & -0.58 & 0.00 & -0.17 & -0.44 & 0.00 & 0.18 & 0.48 \\
\hline & & & 16 & & & 17 & & & 18 & \\
\hline & & & B2 & & & A1 & & & B2 & \\
\hline Frequ & dencies & -- & 1392.890 & & & +35.26 & & & 491.682 & \\
\hline Red. & masses & -- & 1.153 & & & 2.16 & & & 1.877 & \\
\hline Frc o & consts & -- & 1.319 & & & 2.62 & & & 2.461 & \\
\hline IR In & nten & -- & 0.272 & & & 59.14 & & & 6.396 & \\
\hline Atom & AN & $\mathrm{X}$ & $\mathrm{Y}$ & Z & $\mathrm{X}$ & Y & Z & $\mathrm{X}$ & $\mathrm{Y}$ & Z \\
\hline 1 & 6 & 0.00 & -0.02 & 0.00 & 0.00 & 0.00 & -0.12 & 0.00 & 0.12 & 0.00 \\
\hline 2 & 6 & 0.00 & 0.02 & -0.05 & 0.00 & -0.07 & -0.01 & 0.00 & -0.04 & -0.10 \\
\hline 3 & 6 & 0.00 & 0.04 & 0.00 & 0.00 & 0.00 & -0.06 & 0.00 & 0.16 & 0.00 \\
\hline 4 & 6 & 0.00 & 0.02 & 0.05 & 0.00 & 0.07 & -0.01 & 0.00 & -0.04 & 0.10 \\
\hline 5 & 7 & 0.00 & -0.03 & 0.04 & 0.00 & -0.11 & 0.14 & 0.00 & -0.03 & -0.08 \\
\hline 6 & 7 & 0.00 & -0.03 & -0.04 & 0.00 & 0.11 & 0.14 & 0.00 & -0.03 & 0.08 \\
\hline 7 & 1 & 0.00 & 0.70 & 0.00 & 0.00 & 0.00 & -0.13 & 0.00 & -0.68 & 0.00 \\
\hline 8 & 1 & 0.00 & -0.21 & 0.41 & 0.00 & 0.23 & -0.62 & 0.00 & -0.21 & 0.22 \\
\hline 9 & 1 & 0.00 & -0.26 & 0.00 & 0.00 & 0.00 & -0.08 & 0.00 & -0.52 & 0.00 \\
\hline 10 & 1 & 0.00 & -0.21 & -0.41 & 0.00 & -0.23 & -0.62 & 0.00 & -0.21 & -0.2 \\
\hline & & & 19 & & & 20 & & & 21 & \\
\hline & & & $\mathrm{A} 1$ & & & B2 & & & A1 & \\
\hline Frequ & tencies & -- & 1607.70 & & & 507.76 & & & 151.571 & \\
\hline Red. & masses & -- & 5.08 & & & 5.51 & & & 1.088 & \\
\hline Frc C & zonsts & -- & 7.74 & & & 8.40 & & & 6.371 & \\
\hline IR In & nten & -- & 46.36 & & & 85.01 & & & 13.959 & \\
\hline Atom & AN & $\mathrm{X}$ & $Y$ & Z & $\mathrm{X}$ & Y & Z & $\mathrm{X}$ & $Y$ & Z \\
\hline 1 & 6 & 0.00 & 0.00 & 0.09 & 0.00 & 0.32 & 0.00 & 0.00 & 0.00 & -0.01 \\
\hline 2 & 6 & 0.00 & -0.11 & 0.32 & 0.00 & 0.21 & -0.10 & 0.00 & -0.05 & -0.02 \\
\hline 3 & 6 & 0.00 & 0.00 & -0.18 & 0.00 & -0.38 & 0.00 & 0.00 & 0.00 & 0.02 \\
\hline 4 & 6 & 0.00 & 0.11 & 0.32 & 0.00 & 0.21 & 0.10 & 0.00 & 0.05 & -0.02 \\
\hline 5 & 7 & 0.00 & 0.03 & -0.20 & 0.00 & -0.16 & 0.04 & 0.00 & 0.00 & 0.0 \\
\hline 6 & 7 & 0.00 & -0.03 & -0.20 & 0.00 & -0.16 & -0.04 & 0.00 & 0.00 & 0.0 \\
\hline 7 & 1 & 0.00 & 0.00 & 0.08 & 0.00 & -0.41 & 0.00 & 0.00 & 0.00 & 0.1 \\
\hline 8 & 1 & 0.00 & 0.26 & -0.47 & 0.00 & 0.02 & 0.34 & 0.00 & 0.60 & 0.3 \\
\hline 9 & 1 & 0.00 & 0.00 & -0.22 & 0.00 & 0.44 & 0.00 & 0.00 & 0.00 & -0.2 \\
\hline 10 & 1 & 0.00 & -0.26 & -0.47 & 0.00 & 0.02 & -0.34 & 0.00 & -0.60 & 0.3 \\
\hline
\end{tabular}




\begin{tabular}{|c|c|c|c|c|c|c|c|c|c|c|}
\hline & \multicolumn{3}{|c|}{22} & \multicolumn{3}{|c|}{23} & \multicolumn{3}{|c|}{24} \\
\hline & & \multicolumn{3}{|c|}{ B2 } & \multicolumn{3}{|c|}{ A1 } & \multicolumn{3}{|c|}{ A1 } \\
\hline \multirow{2}{*}{\multicolumn{2}{|c|}{$\begin{array}{l}\text { Frequencies } \\
\text { Red. masses }\end{array}$}} & -- & \multicolumn{2}{|c|}{3154.7726} & \multicolumn{3}{|c|}{3167.4200} & \multicolumn{3}{|c|}{3197.5350} \\
\hline & & -- & \multirow{2}{*}{\multicolumn{2}{|c|}{$\begin{array}{l}1.0918 \\
6.4024\end{array}$}} & \multicolumn{3}{|c|}{1.0917} & \multicolumn{3}{|c|}{1.0964} \\
\hline \multicolumn{2}{|c|}{ Frc consts } & -- & & & \multirow{2}{*}{\multicolumn{3}{|c|}{$\begin{array}{r}6.4533 \\
13.7417\end{array}$}} & & 6.60 & \\
\hline \multicolumn{2}{|c|}{ IR Inten } & -- & \multicolumn{2}{|c|}{18.1584} & & & & \multicolumn{3}{|c|}{$\begin{array}{l}0.6045 \\
9.0240\end{array}$} \\
\hline Atom & AN & $\mathrm{x}$ & Y & z & $\mathrm{x}$ & $\mathrm{Y}$ & Z & $\mathrm{x}$ & $\mathrm{Y}$ & $\mathrm{z}$ \\
\hline 1 & 6 & 0.00 & 0.00 & 0.00 & 0.00 & 0.00 & -0.09 & 0.00 & 0.00 & 0.00 \\
\hline 2 & 6 & 0.00 & 0.06 & 0.03 & 0.00 & 0.01 & 0.00 & 0.00 & 0.02 & 0.00 \\
\hline 3 & 6 & 0.00 & 0.00 & 0.00 & 0.00 & 0.00 & -0.01 & 0.00 & 0.00 & 0.09 \\
\hline 4 & 6 & 0.00 & 0.06 & -0.03 & 0.00 & -0.01 & 0.00 & 0.00 & -0.02 & 0.00 \\
\hline 5 & 7 & 0.00 & 0.00 & 0.00 & 0.00 & 0.00 & 0.00 & 0.00 & 0.00 & 0.00 \\
\hline 6 & 7 & 0.00 & 0.00 & 0.00 & 0.00 & 0.00 & 0.00 & 0.00 & 0.00 & 0.00 \\
\hline 7 & 1 & 0.00 & 0.00 & 0.00 & 0.00 & 0.00 & 0.99 & 0.00 & 0.00 & 0.04 \\
\hline 8 & 1 & 0.00 & -0.63 & -0.32 & 0.00 & -0.07 & -0.04 & 0.00 & -0.16 & -0.08 \\
\hline 9 & 1 & 0.00 & 0.01 & 0.00 & 0.00 & 0.00 & 0.08 & 0.00 & 0.00 & -0.96 \\
\hline 10 & 1 & 0.00 & -0.63 & 0.32 & 0.00 & 0.07 & -0.04 & 0.00 & 0.16 & -0.08 \\
\hline
\end{tabular}




\section{2-bromopyrimidine:}

\subsection{Geometry}

optimised Z-matrix at the b3lyp/6-311++g $(d, p)$ level of theory

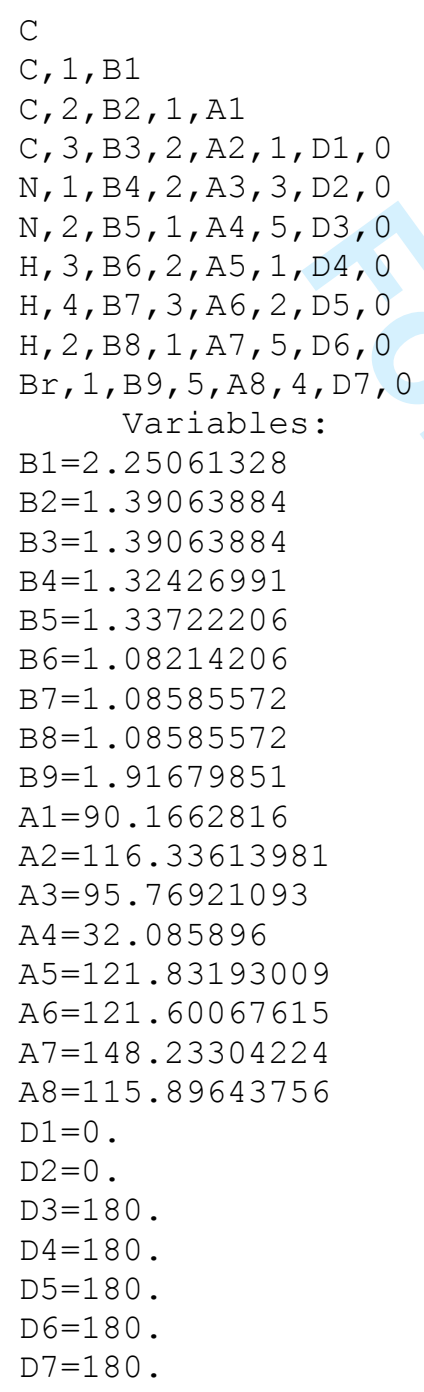

\subsection{Total Energy}

$\mathrm{E}(\mathrm{RB}+\mathrm{HF}-\mathrm{LYP})=-2837.93615700$ Hartrees

\subsection{Frequencies}

Output from the "b3lyp/6-311++g(d,p) freq" calculation

\section{1}

B1

\begin{tabular}{|c|c|c|c|c|}
\hline Ereq & uencies & - & 141.9332 & \\
\hline Red. & masses & ; -- & 6.3832 & \\
\hline FrC & consts & -- & 0.0758 & \\
\hline IR I & nten & -- & 5.1145 & \\
\hline Atom & AN & X & Y & Z \\
\hline 1 & 6 & -0.29 & 0.00 & \\
\hline 2 & 6 & 0.03 & 0.00 & 4 \\
\hline 3 & 6 & 0.37 & 0.00 & \\
\hline
\end{tabular}

2

B2

270.5296

7.7210

0.3329

5.0751

$\begin{array}{lll}X & Y & Z\end{array}$

$\begin{array}{lll}0.00 & 0.36 & 0.00\end{array}$

$0.00-0.02-0.22$

$0.00-0.15 \quad 0.00$
3

A1

322.6271

15.1030

0.9262

5.9056

$\begin{array}{llll}X & Y & \text { Z }\end{array}$

$0.00 \quad 0.00 \quad 0.18$

0.00

0.04

0.00

0.33 


4
5
6
7
8
9
10

$$
\begin{array}{r}
0.03 \\
-0.31 \\
-0.31 \\
0.76 \\
0.05 \\
0.05 \\
0.08
\end{array}
$$

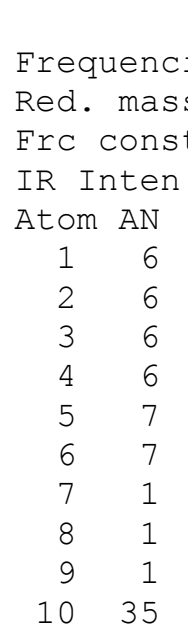$$
\begin{array}{rr}
4 \\
\text { A2 } \\
\quad 409.638
\end{array}
$$$$
409.6389
$$

4.2212

0.4173

0.0000

$$
\begin{array}{llll}
X & Y & Z
\end{array}
$$

0.00

$-0.23$

0.00

0.23

$-0.28$

0.28

0.00

0.61

$-0.61$

0.00

0.00

0.00

0.00

0.00

0.00

0.00

0.00

0.00

0.00

0.00

$$
7
$$

A1

Frequencies --

Red. masses --

Frc consts --

IR Inten

Atom AN

$\begin{array}{rr}1 & 6 \\ 2 & 6 \\ 3 & 6 \\ 4 & 6 \\ 5 & 7 \\ 6 & 7 \\ 7 & 1 \\ 8 & 1 \\ 9 & 1 \\ 10 & 35\end{array}$

$--$

749.3143

7.8907

2.6103

37.9108

$\begin{array}{lll}\text { Y Z } & -9108\end{array}$

$\begin{array}{lll}0.00 & 0.00 & 0.36\end{array}$

0.00

0.00

0.00

0.00

0.00

0.00

0.00

0.00

0.00

$-0.29$

$0.00-0.38$

$0.29 \quad 0.04$

0.27

$-0.27$

0.00
0.15

0.15

$-0.15$

0.00

A2

Frequencies --

Red. masses --

Frc consts --

IR Inten

Atom AN

$\mathrm{X}$

$\begin{array}{lll}1 & 6 & 0.00 \\ 2 & 6 & 0.13\end{array}$

36

$\begin{array}{ll}4 & 6 \\ 5 & 7\end{array}$

67

$\begin{array}{ll}7 & 1 \\ 8 & 1\end{array}$

$\begin{array}{ll}8 & 1 \\ 9 & 1\end{array}$

$10 \quad 35$

$$
0.00
$$

$-0.13$

0.02

$-0.02$

0.00

0.70

$-0.70$

0.00

1.3704

0.8033

0.0000

$\begin{array}{lll}\text { Y } & \mathrm{Z} \\ 0.00 & 0.00\end{array}$

$0.00 \quad 0.00$

$0.00 \quad 0.00$

$0.00 \quad 0.00$

$0.00 \quad 0.00$

$0.00 \quad 0.00$

$0.00 \quad 0.00$

$0.00 \quad 0.00$

$0.00 \quad 0.00$

$0.00 \quad 0.00$

$0.00 \quad 0.00$

13

A1

Frequencies -- 1087.0553

Red. masses --

2.9448

2.0503

$$
\begin{array}{rrr}
0.00 & -0.02 & 0.22 \\
0.00 & 0.27 & 0.19 \\
0.00 & 0.27 & -0.19 \\
0.00 & -0.35 & 0.00 \\
0.00 & -0.12 & 0.42 \\
0.00 & -0.12 & -0.42 \\
0.00 & -0.12 & 0.00
\end{array}
$$

B1

472.2586

3.0790

0.4046

1.8957

$\mathrm{x}$

$\mathrm{Y}$

Z

0.30
-0.15
0.22

0.00

0.00

0.00

0.00

0.00

0.00

0.00

0.00

0.00

0.00

8

B1

784.0197

7.6713

2.7783

11.1410

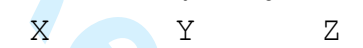

0.51

0.20

$-0.23$

0.20

$-0.30$

$-0.30$

$-0.08$

0.46

0.46

$-0.01$

0.00

0.00

0.00

0.00

0.00

0.00

0.00

0.00

0.00

0.00

0.00

0.00

0.00

0.00

0.00

0.00

0.00

0.00

0.00

0.00

11

B1

998.1127

1.4104

0.8278

0.1154

$\begin{array}{ccc}X & Y & Z \\ -0.04 & 0.00 & 0.00\end{array}$

0.10

$-0.13$

0.10

0.00

0.00

0.59

$-0.56$

$-0.56$

0.00

0.00

0.00

0.00

0.00

0.00

0.00

0.00

0.00

0.00

14

B2

1109.2006

1. 4452

1.0476

$$
\begin{array}{rrr}
0.00 & -0.04 & 0.33 \\
0.00 & -0.06 & 0.30 \\
0.00 & 0.06 & 0.30 \\
0.00 & 0.00 & 0.39 \\
0.00 & -0.01 & 0.28 \\
0.00 & 0.01 & 0.28 \\
0.00 & 0.00 & -0.30
\end{array}
$$$$
\text { B2 }
$$

633.7788

8.2498

1.9524

9.8586

$\begin{array}{lll}X & Y\end{array}$

$\begin{array}{lll}0.00 & -0.10 & 0.00\end{array}$

$\begin{array}{llll}0.00 & 0.26 & -0.26\end{array}$

$0.00 \quad 0.20 \quad 0.00$

$\begin{array}{rrr}0.00 & 0.26 & 0.26\end{array}$

$\begin{array}{lll}0.00 & -0.26 & 0.27\end{array}$

$\begin{array}{llll}0.00 & -0.26 & -0.27\end{array}$

$\begin{array}{llll}0.00 & -0.30 & 0.00\end{array}$

$\begin{array}{lll}0.00 & 0.39 & 0.02\end{array}$

$\begin{array}{lll}0.00 & 0.39 & -0.02\end{array}$

$\begin{array}{lll}0.00 & -0.01 & 0.00\end{array}$

9

B1

818.4156

1.2156

0.4797

27.2525

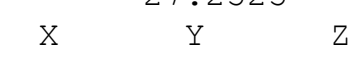

$\begin{array}{lll}-0.03 & 0.00 & 0.00\end{array}$

0.08

0.06

0.08

$-0.03$

$-0.03$

$-0.85$

$-0.36$

$-0.36$

0.00

0.00

0.00

0.00

$0.00 \quad 0.00$

$0.00 \quad 0.00$

$0.00 \quad 0.00$

$0.00 \quad 0.00$

$0.00 \quad 0.00$

$0.00 \quad 0.00$

12

A 1

1002.1739

9.9849

5.9085

0.3353

$\begin{array}{lll}X & Y & \end{array}$

$\begin{array}{lll}0.00 & 0.00 & -0.08\end{array}$

$\begin{array}{lll}0.00 & 0.05 & 0.04\end{array}$

$\begin{array}{lll}0.00 & 0.00 & 0.47\end{array}$

$\begin{array}{lll}0.00 & -0.05 & 0.04\end{array}$

$\begin{array}{lll}0.00 & 0.44 & -0.23\end{array}$

$\begin{array}{llll}0.00 & -0.44 & -0.23\end{array}$

$\begin{array}{lll}0.00 & 0.00 & 0.50\end{array}$

$\begin{array}{lll}0.00 & -0.07 & 0.09\end{array}$

$\begin{array}{lll}0.00 & 0.07 & 0.09\end{array}$

$\begin{array}{lll}0.00 & 0.00 & 0.00\end{array}$

15

A1

1169.1629

3.8904

3.1333 


\begin{tabular}{rrrrr}
\multicolumn{3}{r}{ IR Inten } & \multicolumn{3}{c}{ In } & \multicolumn{2}{c}{7.0117} \\
Atom & AN & X & \multicolumn{1}{c}{$Y$} & \multicolumn{1}{c}{$Z$} \\
1 & 6 & 0.00 & 0.00 & 0.10 \\
2 & 6 & 0.00 & 0.26 & -0.03 \\
3 & 6 & 0.00 & 0.00 & -0.14 \\
4 & 6 & 0.00 & -0.26 & -0.03 \\
5 & 7 & 0.00 & 0.06 & 0.03 \\
6 & 7 & 0.00 & -0.06 & 0.03 \\
7 & 1 & 0.00 & 0.00 & -0.16 \\
8 & 1 & 0.00 & -0.49 & 0.40 \\
9 & 1 & 0.00 & 0.49 & 0.40 \\
10 & 35 & 0.00 & 0.00 & 0.00 \\
& & & 16 &
\end{tabular}

\begin{tabular}{ccr} 
& \multicolumn{3}{c}{0.6871} \\
$X$ & \multicolumn{1}{c}{$Y$} & \multicolumn{1}{c}{$Z$} \\
0.00 & 0.08 & 0.00 \\
0.00 & -0.07 & 0.01 \\
0.00 & 0.10 & 0.00 \\
0.00 & -0.07 & -0.01 \\
0.00 & -0.04 & 0.07 \\
0.00 & -0.04 & -0.07 \\
0.00 & 0.96 & 0.00 \\
0.00 & -0.12 & 0.08 \\
0.00 & -0.12 & -0.08 \\
0.00 & 0.00 & 0.00 \\
& 17 & \\
& B2
\end{tabular}

1289.5484

1.5900

1.5579

8.2626

IR Inten -- $\quad 0.2547$

Atom AN

\begin{tabular}{rrrrr} 
Atom & AN & \multicolumn{1}{c}{ X } & \multicolumn{1}{c}{ Z } \\
2 & 6 & 0.00 & -0.30 & 0.00 \\
3 & 6 & 0.00 & 0.10 & 0.34 \\
4 & 6 & 0.00 & -0.24 & 0.00 \\
5 & 7 & 0.00 & 0.10 & -0.34 \\
6 & 7 & 0.00 & 0.14 & 0.37 \\
7 & 1 & 0.00 & 0.14 & -0.37 \\
8 & 1 & 0.00 & 0.22 & 0.00 \\
9 & 1 & 0.00 & 0.11 & -0.32 \\
10 & 35 & 0.00 & 0.00 & 0.00 \\
& & & 19 & \\
& & & B2 &
\end{tabular}

Frequencies -- 1452.1664

Red. masses -- 1.8935

Frc consts -- $\quad 2.3526$

IR Inten

Atom AN

$\begin{array}{rr}1 & 6 \\ 2 & 6 \\ 3 & 6 \\ 4 & 6 \\ 5 & 7 \\ 6 & 7 \\ 7 & 1 \\ 8 & 1 \\ 9 & 1 \\ 10 & 35\end{array}$

$--$

0.4779

$\mathrm{X}$
0.00

$\mathrm{Y}$

0.12

0.00

0.00

0.00

0.00

0.00

0.00

0.00

0.00

0.00

$-0.01$

0.14

$-0.01$

$-0.06$

$-0.06$

$-0.61$

$-0.30$

$-0.30-0.43$

22

A 1

\begin{tabular}{|c|c|c|c|c|}
\hline Freo & uencies & -- & 162.113 & \\
\hline Red. & masses & -- & 1.090 & \\
\hline Irc & consts & -- & 6.422 & \\
\hline IR I & nten & -- & 11.804 & \\
\hline tom & $\mathrm{AN}$ & $\mathrm{X}$ & Y & Z \\
\hline 1 & 6 & 0.00 & 0.00 & 0.00 \\
\hline 2 & 6 & 0.00 & 0.05 & -0.02 \\
\hline 3 & 6 & 0.00 & 0.00 & 0.02 \\
\hline 4 & 6 & 0.00 & -0.05 & -0.02 \\
\hline 5 & 7 & 0.00 & 0.00 & 0.00 \\
\hline 6 & 7 & 0.00 & 0.00 & 0.00 \\
\hline 7 & 1 & 0.00 & 0.00 & -0.24 \\
\hline 8 & 1 & 0.00 & 0.61 & 0.30 \\
\hline 9 & 1 & 0.00 & -0.61 & 0.30 \\
\hline 10 & 35 & 0.00 & 0.00 & 0.00 \\
\hline
\end{tabular}

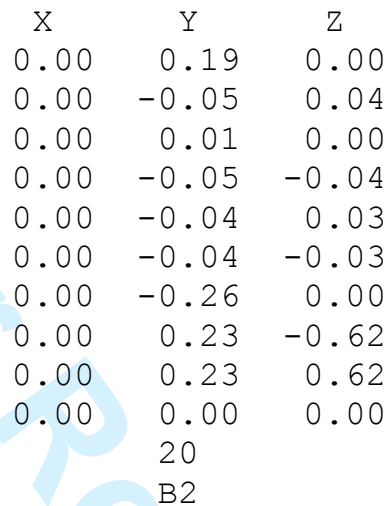

1587.6783

6.2180

9.2347

107.8272

$$
\begin{array}{lll}
X & Y
\end{array}
$$

$\begin{array}{lll}0.00 & -0.29 & 0.00\end{array}$

$0.00 \quad-0.23 \quad-0.09$

$\begin{array}{rrr}0.00 & 0.44 & 0.00\end{array}$

$\begin{array}{llll}0.00 & -0.23 & 0.09\end{array}$

$\begin{array}{lll}0.00 & 0.16 & 0.07\end{array}$

$\begin{array}{rrr}0.00 & 0.16 & -0.07\end{array}$

$\begin{array}{lll}0.00 & -0.56 & 0.00\end{array}$

0.00

0.00

0.00

$0.00 \quad 0.00$

$0.00-0.06$

$0.00 \quad 0.00$

0.00

0.00

0.00

0.00

0.00

0.00

0.00
3165.0691

$\begin{array}{lll}X & Y\end{array}$
$-0.05$

$-0.05$

0.00

$$
23
$$

B2

1.0922

6.4467

12.4157

$-0.33$

0.33

0.00

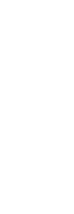

Z

0.00

0.03

0.00

$-0.06$

0.00

0.00

$-0.03$

0.00

$-0.01$

0.63

0.00

0.31

$-0.31$
0.63

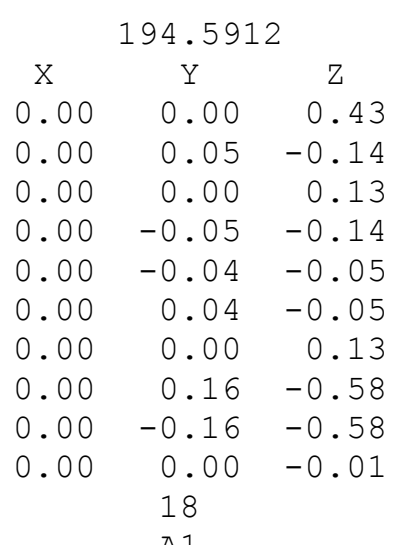

A 1

1417.8813

2.1216

2.5130

242.4240

\begin{tabular}{crr}
$X$ & \multicolumn{1}{c}{$Y$} & $Z$ \\
0.00 & 0.00 & 0.11 \\
0.00 & -0.07 & 0.03 \\
0.00 & 0.00 & 0.06 \\
0.00 & 0.07 & 0.03 \\
0.00 & -0.10 & -0.15 \\
0.00 & 0.10 & -0.15 \\
0.00 & 0.00 & 0.07 \\
0.00 & -0.23 & 0.63 \\
0.00 & 0.23 & 0.63 \\
0.00 & 0.00 & 0.00 \\
& 21 &
\end{tabular}

A1

1596.9566

4.7210

7.0937

141.3138

$$
\begin{array}{lll}
X & Y
\end{array}
$$

$\begin{array}{lll}0.00 & 0.00 & 0.05\end{array}$

$\begin{array}{lll}0.00 & 0.11 & 0.32\end{array}$

$\begin{array}{rrr}0.00 & 0.00 & -0.18\end{array}$

$\begin{array}{lll}0.00 & -0.11 & 0.32\end{array}$

$\begin{array}{rrr}0.00 & -0.11 & -0.32 \\ 0.00 & -0.02 & -0.18\end{array}$

$\begin{array}{lll}0.00 & 0.02 & -0.18\end{array}$

$\begin{array}{llll}0.00 & 0.00 & -0.22\end{array}$

$\begin{array}{lll}0.00 & 0.26 & -0.49\end{array}$

$\begin{array}{lll}0.00 & -0.26 & -0.49\end{array}$

$\begin{array}{lll}0.00 & 0.00 & 0.00\end{array}$

$$
24
$$

A1

3207.8318

1.0965

6.6477

5.1310

$\begin{array}{lll}X & Y\end{array}$

$\begin{array}{lll}0.00 & 0.00 & 0.00\end{array}$

$\begin{array}{lll}0.00 & 0.02 & 0.00\end{array}$

$\begin{array}{lll}0.00 & 0.00 & -0.09\end{array}$

$\begin{array}{lll}0.00 & -0.02 & 0.00\end{array}$

$0.00 \quad 0.00 \quad 0.00$

$0.00 \quad 0.00 \quad 0.00$

$0.00 \quad 0.00 \quad 0.97$

$\begin{array}{lll}0.00 & 0.15 & 0.07\end{array}$

$\begin{array}{lll}0.00 & -0.15 & 0.07\end{array}$

$0.00 \quad 0.00 \quad 0.00$ 


\section{5-bromopyrimidine:}

\subsection{Geometry}

optimised Z-matrix at the b3lyp/6-311++g $(d, p)$ level of theory

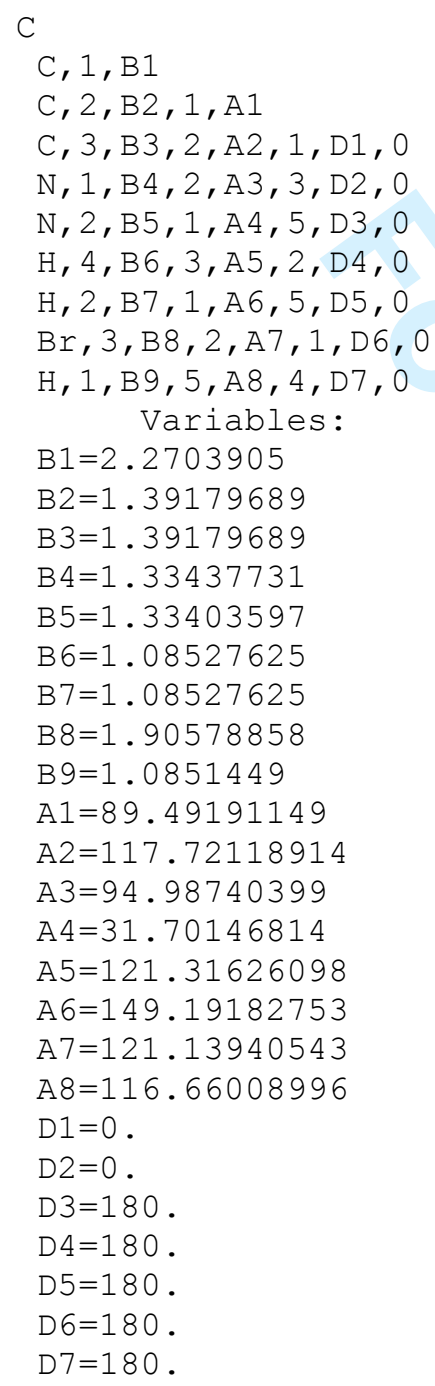

\subsection{Total Energy}

$\mathrm{E}(\mathrm{RB}+\mathrm{HF}-\mathrm{LYP})=-2837.93398026$ Hartrees

\subsection{Frequencies}

Output from the "b3lyp/6-311++g(d,p) freq" calculation

\begin{tabular}{|c|c|c|c|c|c|c|c|c|c|}
\hline & & 1 & & & 2 & & & 3 & \\
\hline & & B1 & & & B2 & & & A1 & \\
\hline Frequencies & -- & 163.3838 & & & 241.86 & & & 321.2182 & \\
\hline Red. masses & -- & 4.1375 & & & 6.25 & & & 13.3842 & \\
\hline Frc consts & -- & 0.0651 & & & 0.21 & & & 0.8137 & \\
\hline IR Inten & -- & 0.2971 & & & 1.12 & & & 2.6204 & \\
\hline Atom AN & $\mathrm{X}$ & $\mathrm{Y}$ & Z & $\mathrm{x}$ & $\mathrm{Y}$ & Z & $\mathrm{x}$ & $\mathrm{Y}$ & Z \\
\hline 16 & 0.27 & 0.00 & 0.00 & 0.00 & -0.12 & 0.00 & 0.00 & 0.00 & 0.37 \\
\hline 6 & -0.24 & 0.00 & 0.00 & 0.00 & 0.24 & -0.18 & 0.00 & 0.04 & 0.28 \\
\hline 6 & -0.25 & 0.00 & 0.00 & 0.00 & 0.34 & 0.00 & 0.00 & 0.00 & 0.12 \\
\hline
\end{tabular}




$\begin{array}{rrrrr}4 & 6 & -0.24 & 0.00 & 0.00 \\ 5 & 7 & 0.04 & 0.00 & 0.00 \\ 6 & 7 & 0.04 & 0.00 & 0.00 \\ 7 & 1 & -0.40 & 0.00 & 0.00 \\ 8 & 1 & -0.40 & 0.00 & 0.00 \\ 9 & 35 & 0.06 & 0.00 & 0.00 \\ 10 & 1 & 0.64 & 0.00 & 0.00\end{array}$

$$
\begin{array}{lrr}
0.00 & 0.24 & 0.18 \\
0.00 & -0.02 & 0.20 \\
0.00 & -0.02 & -0.20 \\
0.00 & 0.34 & 0.37 \\
0.00 & 0.34 & -0.37 \\
0.00 & -0.10 & 0.00 \\
0.00 & -0.30 & 0.00
\end{array}
$$$$
\text { A2 }
$$

Frequencies --

Red. masses --

Frc consts --

Atom AN

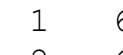

26

36

46

57

67

71

$\begin{array}{lr}8 & 1 \\ 9 & 35\end{array}$

$$
\begin{array}{rr}
10 & 1
\end{array}
$$

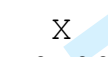

0.00

0.23

0.00

$-0.23$

0.28

$-0.28$

$-0.61$

0.61

0.00

0.00

A2

412.6071

4.2054

0.4218

0.0000

Y Z

$0.00 \quad 0.00$

$0.00 \quad 0.00$

$0.00 \quad 0.00$

$0.00 \quad 0.00$

$0.00 \quad 0.00$

$0.00 \quad 0.00$

$0.00 \quad 0.00$

0.00

0.00

0.00

7

B1

Frequencies --

Frc consts --

Atom AN

$26-0.13$
Red. masses --

IR Inten

$\begin{array}{rrr}1 & 6 & -0.15 \\ 2 & 6 & -0.12 \\ 3 & 6 & 0.12 \\ 4 & 6 & -0.12 \\ 5 & 7 & 0.17 \\ 6 & 7 & 0.17 \\ 7 & 1 & -0.47 \\ 8 & 1 & -0.47 \\ 9 & 35 & 0.00 \\ 10 & 1 & -0.66\end{array}$

101

$-0.66$

Frequencies --

Red. masses --

Frc consts --

IR Inten

Atom AN

$\begin{array}{lll}1 & 6 & X \\ 2 & 6 & 0.00\end{array}$

360.00

$\begin{array}{lll}4 & 6 & 0.13\end{array}$

$\begin{array}{lll}5 & 7 & -0.02\end{array}$

67

$\begin{array}{ll}7 & 1\end{array}$

0.02

$-0.70$

0.70

0.00

0.00

729.9382

2.4451

0.7676

29.5164

$$
\text { Y Z }
$$

$0.00 \quad 0.00$

0.00

0.00

0.00

0.00

0.00

0.00

0.00

0.00

0.00

10

A2

975.1222

1.3708

0.7680

0.0000

Y Z

$0.00 \quad 0.00$

$0.00 \quad 0.00$

$0.00 \quad 0.00$

$0.00 \quad 0.00$

$0.00 \quad 0.00$

$0.00 \quad 0.00$

0.00

0.00

0.00

0.00

13

A1

Frequencies -- 1099.9895

5.2004

3.7074

0.00

0.00
B1

420.6792

4.3323

0.4517

0.4197

$\begin{array}{lll}X & Y\end{array}$

0.17

$-0.07$

0.46

$-0.07$

$-0.15$

$-0.15$

$-0.49$

$-0.49$

$-0.02$

0.47

0.00

0.00

0.00

0.00

0.00

0.00

0.00

0.00

0.00

0.00

8

A1

744.8655

9.5447

3.1201

6.2089

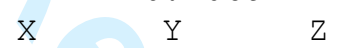

$0.00 \quad 0.00 \quad-0.33$

$0.00-0.32 \quad 0.05$

$\begin{array}{lll}0.00 & 0.00 & 0.42\end{array}$

$\begin{array}{lll}0.00 & 0.33 & 0.06\end{array}$

0.00

0.00

0.00

0.00

0.00

$-0.33$

0.19

$-0.19$

0.0

0.00 11

B1

992.7439

1.4830

0.8611

0.0048

$\mathrm{X}$

0.18

$-0.06$

0.03

$-0.06$

$-0.03$

$-0.03$

0.34

0.34

0.00

$-0.85$

$\mathrm{Y}$

0.00

0.00

0.00

0.00

0.00

0.00

0.00

0.00

0.00

0.00

14

A1

1161.1637

2.2578

1.7936 $\begin{array}{lll}0.00 & 0.32 & 0.05\end{array}$

$$
\begin{array}{rrr}
0.00 & -0.04 & 0.28 \\
0.00 & -0.04 & 0.32 \\
0.00 & 0.04 & 0.32 \\
0.00 & 0.00 & 0.37 \\
0.00 & 0.00 & 0.37 \\
0.00 & 0.00 & -0.29 \\
0.00 & 0.00 & 0.37
\end{array}
$$

$$
\text { B2 }
$$

629.1750

8.9424

2.0857

13.8198

$\begin{array}{lll}X & Y\end{array}$

$\begin{array}{lrr}0.00 & 0.13 & 0.00\end{array}$

$0.00 \quad-0.24 \quad-0.25$

$\begin{array}{lll}0.00 & -0.21 & 0.00\end{array}$

$\begin{array}{llll}0.00 & -0.24 & 0.25\end{array}$

$\begin{array}{lll}0.00 & 0.30 & 0.30\end{array}$

$\begin{array}{lll}0.00 & 0.30 & -0.30\end{array}$

$\begin{array}{lll}0.00 & -0.37 \quad 0.02\end{array}$

$\begin{array}{llll}0.00 & -0.37 & -0.02\end{array}$

$\begin{array}{lll}0.00 & -0.01 & 0.00\end{array}$

0.00

$-0.26$

B1

907.7513

1.6123

0.7828

6.6819

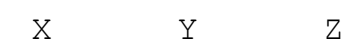

$\begin{array}{lll}0.09 & 0.00 & 0.00\end{array}$

$\begin{array}{lll}0.13 & 0.00 & 0.00\end{array}$

$\begin{array}{lll}-0.10 & 0.00 & 0.00\end{array}$

$\begin{array}{lll}0.13 & 0.00 & 0.00\end{array}$

$\begin{array}{lll}-0.05 & 0.00 & 0.00\end{array}$

$\begin{array}{lll}-0.05 & 0.00 & 0.00\end{array}$

$\begin{array}{lll}-0.60 & 0.00 & 0.00\end{array}$

$\begin{array}{lll}-0.60 & 0.00 & 0.00\end{array}$

$0.00 \quad 0.00 \quad 0.00$

$0.00 \quad 0.00$

12

A 1

1028.7472

8.2121

5.1206

61.2852

$\begin{array}{llll}X & Y & \end{array}$

$\begin{array}{lll}0.00 & 0.00 & -0.03\end{array}$

$\begin{array}{llll}0.00 & 0.24 & -0.01\end{array}$

$\begin{array}{llll}0.00 & 0.00 & -0.38\end{array}$

$\begin{array}{llll}0.00 & -0.24 & -0.01\end{array}$

$\begin{array}{rrr}0.00 & 0.37 & 0.17\end{array}$

$\begin{array}{lll}0.00 & -0.37 & 0.17\end{array}$

$\begin{array}{llll}0.00 & -0.37 & -0.26\end{array}$

$\begin{array}{lll}0.00 & 0.37 & -0.26\end{array}$

$\begin{array}{rrr}0.00 & 0.00 \quad 0.02\end{array}$

$\begin{array}{llll}0.00 & 0.00 & -0.03\end{array}$

15

B2

1205.9251

2.3954

2.0524 


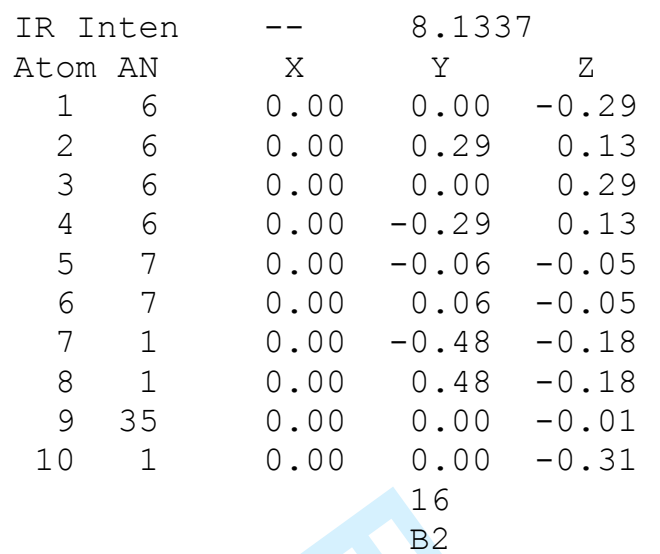

\begin{tabular}{crr}
\multicolumn{3}{c}{30.2899} \\
$X$ & \multicolumn{1}{c}{$Y$} & \multicolumn{1}{c}{$Z$} \\
0.00 & 0.00 & 0.23 \\
0.00 & 0.02 & -0.10 \\
0.00 & 0.00 & 0.17 \\
0.00 & -0.02 & -0.10 \\
0.00 & 0.04 & -0.04 \\
0.00 & -0.04 & -0.04 \\
0.00 & -0.27 & -0.58 \\
0.00 & 0.27 & -0.58 \\
0.00 & 0.00 & 0.00 \\
0.00 & 0.00 & 0.25 \\
& 17 & \\
& B2
\end{tabular}

1360.9646

1.2322

1.3447

3.1059

IR Inten -- 2.3611

Atom AN

\begin{tabular}{rrrrr} 
Atom & AN & \multicolumn{1}{c}{ X } & \multicolumn{1}{c}{ Y } \\
1 & 6 & 0.00 & 0.40 & 0.00 \\
2 & 6 & 0.00 & -0.17 & 0.09 \\
3 & 6 & 0.00 & 0.25 & 0.00 \\
4 & 6 & 0.00 & -0.17 & -0.09 \\
5 & 7 & 0.00 & -0.16 & 0.13 \\
6 & 7 & 0.00 & -0.16 & -0.13 \\
7 & 1 & 0.00 & 0.04 & 0.36 \\
8 & 1 & 0.00 & 0.04 & -0.36 \\
9 & 35 & 0.00 & 0.00 & 0.00 \\
10 & 1 & 0.00 & 0.59 & 0.00 \\
& & & 19 &
\end{tabular}

Frequencies -- 1450.7022

Red. masses -- 1.8683

Frc consts -- $\quad 2.3166$

IR Inten

Atom AN

$\begin{array}{rr}1 & 6 \\ 2 & 6 \\ 3 & 6 \\ 4 & 6 \\ 5 & 7 \\ 6 & 7 \\ 7 & 1 \\ 8 & 1 \\ 9 & 35 \\ 10 & 1\end{array}$

$--$

13.8141

$$
\begin{array}{ccc}
X & Y & Z \\
0.00 & 0.08 & 0.00
\end{array}
$$

0.00

0.00

0.00

0.00

0.00

0.00

0.00

0.00

0.00

0.00

0.08

$-0.07$

0.16

$-0.07$

0.00

0.00

$-0.15$

$-0.15$

0.00

$-0.93$

22

B2

\begin{tabular}{|c|c|c|c|c|}
\hline Freq & ncies & -- & 71.212 & \\
\hline Red. & masses & -- & 1.092 & \\
\hline $\operatorname{Frc}$ & consts & -- & 6.472 & \\
\hline IR I & nten & -- & 2.68 & \\
\hline Atom & AN & $\mathrm{X}$ & $\mathrm{Y}$ & Z \\
\hline 1 & 6 & 0.00 & 0.00 & . \\
\hline 2 & 6 & 0.00 & -0.06 & -0. \\
\hline 3 & 6 & 0.00 & 0.00 & 0 . \\
\hline 4 & 6 & 0.00 & -0.06 & 0 . \\
\hline 5 & 7 & 0.00 & 0.00 & 0. \\
\hline 6 & 7 & 0.00 & 0.00 & 0 . \\
\hline 7 & 1 & 0.00 & 0.63 & -0 \\
\hline 8 & 1 & 0.00 & 0.63 & 0. \\
\hline 9 & 35 & 0.00 & 0.00 & 0. \\
\hline 10 & 1 & 0.00 & 0.00 & 0. \\
\hline
\end{tabular}

\section{$\mathrm{Y}$}

0.00

0.00

0.00

0.00

0.00

0.00

0.00

0.00

0.00

0.00

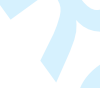

158

581.4764

5.6690

8.3538

1.9578

$\begin{array}{lll}X & Y & Z\end{array}$

0.00

0.00

0.00

0.00

0.00

0.00

0.00

0.00

0.00

0.00

0.00

$-0.11$

0.34

$0.00-0.19$

$\begin{array}{ll}0.11 & 0.34\end{array}$

$\begin{array}{rr}0.05 & -0.22\end{array}$

$\begin{array}{ll}-0.05 & -0.22\end{array}$

$\begin{array}{ll}-0.28 & -0.46\end{array}$

$0.28-0.46$

0.00

0.00

23

A1

3171.2227

1.0910

6.4647

10.4263

$\mathrm{X}$

$$
\mathrm{Y}
$$

0.00

0.00

0.05

0.00

0.00

0.00

0.00

0.00

0.00

0.00

0.00

0.00
$-0.05$

0.00

0.00

0.59

$\begin{array}{lll}0.00 & 0.00\end{array}$

$0.00-0.34$

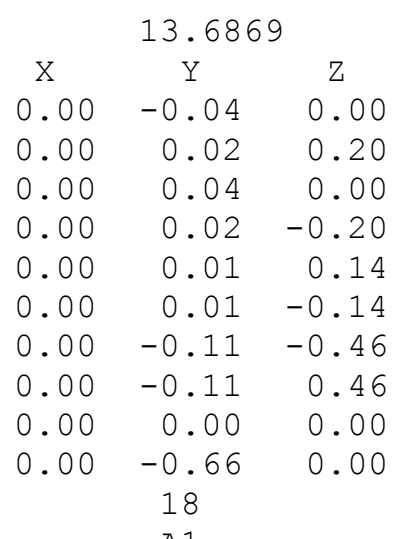

A1

1436.3278

2.1819

2.6521

78.7633

\begin{tabular}{crc}
$X$ & \multicolumn{1}{c}{$Y$} & $Z$ \\
0.00 & 0.00 & 0.12 \\
0.00 & 0.08 & 0.00 \\
0.00 & 0.00 & 0.10 \\
0.00 & -0.08 & 0.00 \\
0.00 & 0.11 & -0.13 \\
0.00 & -0.11 & -0.13 \\
0.00 & 0.23 & 0.63 \\
0.00 & -0.23 & 0.63 \\
0.00 & 0.00 & 0.00 \\
0.00 & 0.00 & 0.12 \\
& \multicolumn{1}{c}{21} & \\
& B2
\end{tabular}

1583.1277

5.8096

8.5788

57.7146

$\begin{array}{lll}X & Y & Z\end{array}$

$\begin{array}{rrr}0.00 & 0.37 & 0.00 \\ 0.00 & 0.20 & -0.12 \\ 0.00 & -0.33 & 0.00\end{array}$

$\begin{array}{lll}0.00 & -0.33 & 0.00\end{array}$

$\begin{array}{lll}0.00 & 0.20 & 0.12\end{array}$

$\begin{array}{lll}0.00 & -0.17 & 0.04\end{array}$

$\begin{array}{lll}0.00 & -0.17 & -0.04\end{array}$

$\begin{array}{lll}0.00 & -0.03 & -0.38\end{array}$

$\begin{array}{lll}0.00 & -0.03 & 0.38\end{array}$

$\begin{array}{lll}0.00 & 0.00 & 0.00\end{array}$

$\begin{array}{llll}0.00 & -0.53 & 0.00\end{array}$

24

A1

3178.9094

1.0935

6.5106

5.7922

$\begin{array}{llll}X & Y & Z\end{array}$

$\begin{array}{lll}0.00 & 0.00 & 0.08\end{array}$

$\begin{array}{lll}0.00 & -0.02 & -0.01\end{array}$

$\begin{array}{lll}0.00 & 0.00 & 0.00\end{array}$

$\begin{array}{lll}0.00 & 0.02 & -0.01\end{array}$

$\begin{array}{lll}0.00 & 0.00 & 0.00\end{array}$

$\begin{array}{lll}0.00 & 0.00 & 0.00\end{array}$

$\begin{array}{lll}0.00 & -0.21 & 0.11\end{array}$

$\begin{array}{lll}0.00 & 0.21 & 0.11\end{array}$

$\begin{array}{lll}0.00 & 0.00 & 0.00\end{array}$

$\begin{array}{llll}0.00 & 0.00 & -0.94\end{array}$ 


\section{2-chloropyrimidine:}

\subsection{Geometry}

optimised Z-matrix at the b3lyp/6-311++g $(d, p)$ level of theory

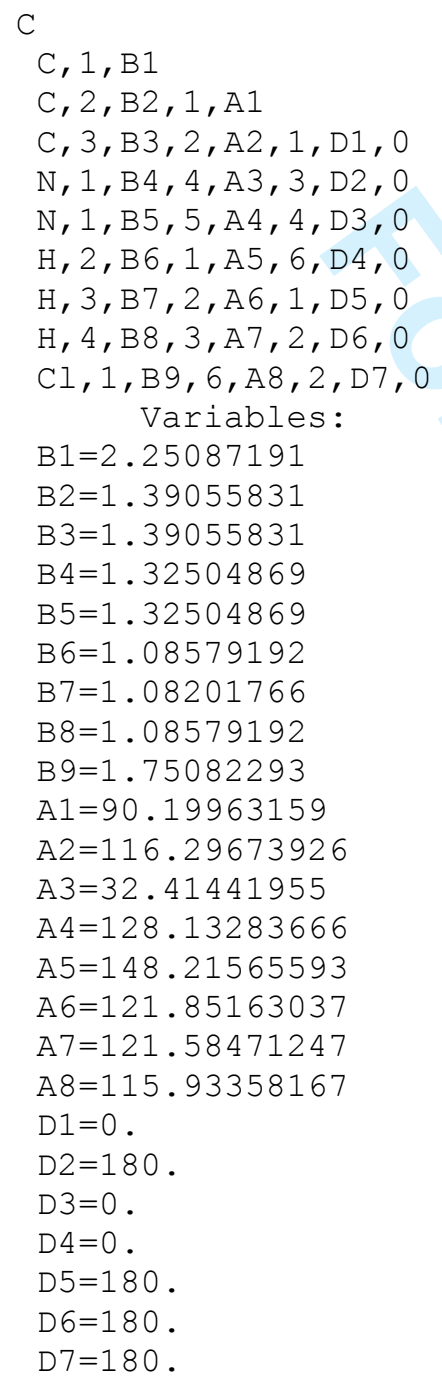

\subsection{Total Energy}

b3lyp/6-311++g $(d, p)$ level of theory

$\mathrm{E}(\mathrm{RB}+\mathrm{HF}-\mathrm{LYP})=-724.017721191$ Hartrees

\subsection{Frequencies}

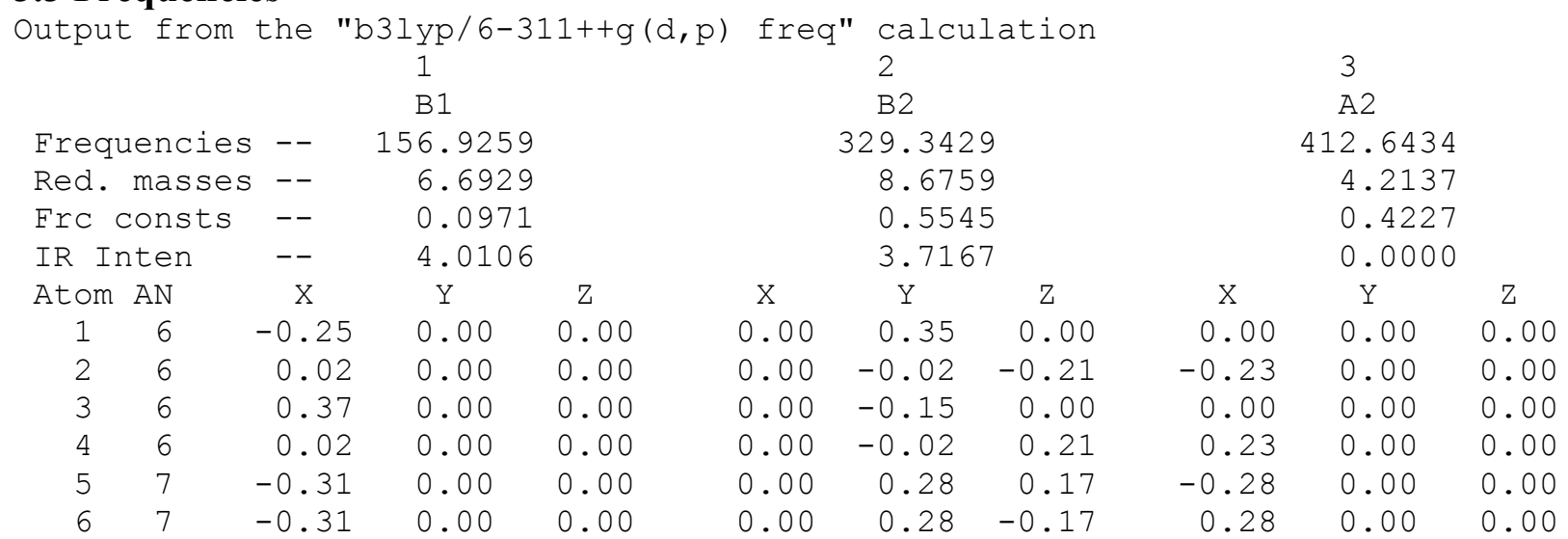




$\begin{array}{rrlll}7 & 1 & 0.01 & 0.00 & 0.00 \\ 8 & 1 & 0.76 & 0.00 & 0.00 \\ 9 & 1 & 0.01 & 0.00 & 0.00 \\ 10 & 17 & 0.17 & 0.00 & 0.00\end{array}$

\begin{tabular}{|c|c|c|c|c|}
\hline & \multicolumn{3}{|c|}{4} \\
\hline Frec & dencies & -- & 440.1012 & \\
\hline Red. & masses & -- & 16.3001 & \\
\hline Frc & consts & -- & 1.8601 & \\
\hline IR & iten & -- & 9.8159 & \\
\hline Aton & AN & $\mathrm{x}$ & Y & Z \\
\hline 1 & 6 & 0.00 & 0.00 & 0.01 \\
\hline 2 & 6 & 0.00 & 0.08 & $0.2 \varepsilon$ \\
\hline 3 & 6 & 0.00 & 0.00 & 0.41 \\
\hline 4 & 6 & 0.00 & -0.08 & $0.2 \varepsilon$ \\
\hline 5 & 7 & 0.00 & -0.11 & 0.23 \\
\hline 6 & 7 & 0.00 & 0.11 & 0.23 \\
\hline 7 & 1 & 0.00 & 0.03 & $0.1 \mathrm{~s}$ \\
\hline 8 & 1 & 0.00 & 0.00 & 0.41 \\
\hline 9 & 1 & 0.00 & -0.03 & 0.19 \\
\hline 10 & 17 & 0.00 & 0.00 & -0.54 \\
\hline
\end{tabular}

A1

Frequencies - -

Red. masses --

Frc consts --

IR Inten

Atom AN

$\begin{array}{rr}1 & 6 \\ 2 & 6 \\ 3 & 6 \\ 4 & 6 \\ 5 & 7 \\ 6 & 7 \\ 7 & 1 \\ 8 & 1 \\ 9 & 1 \\ 10 & 17\end{array}$

771.0900

7.8502

2.7501

41.8704

$$
\mathrm{Y}
$$

0.00

0.00

0.00

0.00

0.00

0.00

0.00

0.00

0.00

0.00

0.00

$-0.29$

0.00

0.29

0.27

$-0.27$

$-0.15$

0.00

0.15

0.00

10

A2

Frequencies --

Red. masses --

Frc consts --

IR Inten

Atom AN

26

36

46

57

67

$\begin{array}{ll}7 & 1 \\ 8 & 1\end{array}$

$\begin{array}{ll}8 & 1 \\ 9 & 1\end{array}$

$10 \quad 17$

998.8

1.3712

0.8060

0.0000

$$
\text { Y Z }
$$

0.00

0.13

0.00

$-0.13$

0.02

$-0.02$

$-0.70$

0.00

0.70

0.00

0.00

0.00

0.00

0.00

0.00

0.00

0.00

0.00

0.00

0.00

13

A1

Frequencies -- 1089.8833

Red. masses -- 2.7526

Frc consts -- 1.9264

IR Inten -- 5.1067

Atom AN

16

$\mathrm{X}$

0.00

$\begin{array}{lll}5 & \text { Y }\end{array}$

$0.00 \quad 0.08$

$$
\begin{array}{rcr}
0.00 & -0.12 & -0.41 \\
0.00 & -0.34 & 0.00 \\
0.00 & -0.12 & 0.41 \\
0.00 & -0.26 & 0.00 \\
\multicolumn{3}{c}{5} \\
\text { B1 } \\
490.9697 \\
\multicolumn{3}{c}{2.9718} \\
& 0.4221 \\
& 1.7882 \\
X & Y & Z \\
0.28 & 0.00 & 0.00 \\
-0.15 & 0.00 & 0.00 \\
0.22 & 0.00 & 0.00 \\
-0.15 & 0.00 & 0.00 \\
0.00 & 0.00 & 0.00 \\
0.00 & 0.00 & 0.00 \\
-0.62 & 0.00 & 0.00 \\
0.22 & 0.00 & 0.00 \\
-0.62 & 0.00 & 0.00 \\
-0.04 & 0.00 & 0.00
\end{array}
$$

$x$
0.28

Z

B1

794.6226

8.8428

3.2897

9.7078

X

Y

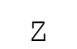

0.56

0.00

0.00

0.22
-0.22

0.00

0.22

0.00

$-0.33$

$-0.33$

0.37

$-0.22$

0.37

$-0.02$

0.00

0.00

0.00

0.00

0.00

0.00

11

B1

1000.7750

1.4171

0.8362

0.1791

$\mathrm{X}$

0.00

0.00

0.00

0.00

0.00

0.00

0.00

0.00

0.00

0.00

0.04

$-0.10$

0.13

$-0.10$

0.00

0.00

0.56

$-0.58$

0.56

0.00

Y

0.00

0.00

0.00

0.00

0.00

0.00

0.00

0.00

0.00

0.00

14

B2

1111.3335

1.4327

1.0425

0.5982

0.00

0.00

0.00

0.00

0.00

0.00

0.00

0.00

0.00

0.00

Y 0.08

$\mathrm{X}$

$\mathrm{Z}$

0.00

$$
\begin{array}{r}
-0.61 \\
0.00 \\
0.61 \\
0.00
\end{array}
$$

0.00

0.00

$0.00 \quad 0.00$

$0.00 \quad 0.00$

$0.00 \quad 0.00$

B2

638.0703

8.1824

1.9628

8.8438

$\mathrm{X}$

0.00

0.00

0.00

0.00

0.00

0.00

0.00

0.00

0.00

0.00

Y

Z

$\begin{array}{ll}-0.09 & 0.00\end{array}$

$\begin{array}{lll}0.26 & -0.27\end{array}$

$\begin{array}{lll}0.20 & 0.00\end{array}$

$\begin{array}{lll}0.26 & 0.27\end{array}$

$\begin{array}{ll}-0.25 & 0.27\end{array}$

$\begin{array}{ll}-0.25 & -0.27\end{array}$

$\begin{array}{lll}0.39 & -0.03\end{array}$

$\begin{array}{ll}-0.31 & 0.00 \\ 0.39 & 0.03\end{array}$

$\begin{array}{rr}0.39 & 0.03\end{array}$

$-0.03$

0.00

B1

818.9335

1.2088

0.4777

30.1620

$\begin{array}{lll}X & Y\end{array}$

$\begin{array}{lll}-0.05 & 0.00 & 0.00\end{array}$

$0.07 \quad 0.00 \quad 0.00$

$0.07 \quad 0.00 \quad 0.00$

$0.07 \quad 0.00 \quad 0.00$

$\begin{array}{lll}-0.02 & 0.00 & 0.00\end{array}$

$\begin{array}{lll}-0.02 & 0.00 & 0.00\end{array}$

$\begin{array}{lll}-0.36 & 0.00 & 0.00\end{array}$

$\begin{array}{lll}-0.85 & 0.00 & 0.00\end{array}$

$\begin{array}{lll}-0.36 & 0.00 & 0.00\end{array}$

$0.00 \quad 0.00 \quad 0.00$

12

A 1

1004.2248

9.9668

5.9220

0.1534

$\begin{array}{lll}\mathrm{X} & \mathrm{Z}\end{array}$

$\begin{array}{llll}0.00 & 0.00 & -0.08\end{array}$

$\begin{array}{lll}0.00 & 0.06 & 0.03\end{array}$

$\begin{array}{lll}0.00 & 0.00 \quad 0.48\end{array}$

$\begin{array}{lll}0.00 & -0.06 & 0.03\end{array}$

$\begin{array}{lll}0.00 & 0.43 & -0.23\end{array}$

$\begin{array}{lll}0.00 & -0.43 & -0.23\end{array}$

$\begin{array}{lll}0.00 & 0.07 & 0.08\end{array}$

$0.00 \quad 0.00 \quad 0.50$ 


$\begin{array}{rrrrr}2 & 6 & 0.00 & 0.24 & -0.02 \\ 3 & 6 & 0.00 & 0.00 & -0.14 \\ 4 & 6 & 0.00 & -0.24 & -0.02 \\ 5 & 7 & 0.00 & 0.06 & 0.04 \\ 6 & 7 & 0.00 & -0.06 & 0.04 \\ 7 & 1 & 0.00 & 0.48 & 0.42 \\ 8 & 1 & 0.00 & 0.00 & -0.17 \\ 9 & 1 & 0.00 & -0.48 & 0.42 \\ 10 & 17 & 0.00 & 0.00 & -0.01 \\ & & & 16 & \\ & & & \text { B2 }\end{array}$

Frequencies -- 1233.1390

Red. masses -- 9.6511

Frc consts -- $\quad 8.6467$

IR Inten -- $\quad 0.7996$

Atom AN

$\begin{array}{rr}1 & 6 \\ 2 & 6 \\ 3 & 6 \\ 4 & 6 \\ 5 & 7 \\ 6 & 7 \\ 7 & 1 \\ 8 & 1 \\ 9 & 1 \\ 10 & 17\end{array}$

$$
10 \quad 17
$$

$\begin{array}{ccc}X & Y & Z \\ 0.00 & -0.31 & 0.00 \\ 0.00 & 0.10 & 0.34\end{array}$

0.00

0.00

0.00

0.00

0.00

0.00

0.00

0.00

$0.10-0.34$

$0.15 \quad 0.37$

$0.15-0.37$

$0.10 \quad 0.30$

0.27

0.10

$-0.01$

19

B2

Frequencies -- 1455.2160

Red. masses --

Frc consts --

IR Inten

Atom AN

$\begin{array}{rrr}1 & 6 & 0 \\ 2 & 6 & 0 \\ 3 & 6 & 0 \\ 4 & 6 & 0 \\ 5 & 7 & 0 \\ 6 & 7 & 0 \\ 7 & 1 & 0 \\ 8 & 1 & 0 \\ 9 & 1 & 0 \\ 10 & 17 & 0\end{array}$

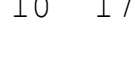

Frequencies

Red. masses --

Frc consts --

IR Inten

Atom AN

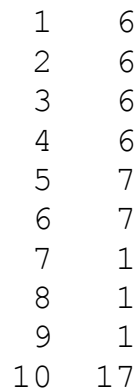

1.9360

2.4155

0.4549

$$
\mathrm{Y}
$$

0.00

0.00

0.00

0.00

0.00

0.00

0.00

0.00

0.00

0.00
10.9331

$\begin{array}{lll}X & Y\end{array}$

$\begin{array}{rrr}0.00 & 0.00 \quad 0.00\end{array}$

0.00

0.00

0.00

0.00

0.00

0.00

0.00

0.00

0.00
$-0.24$

$$
\begin{array}{rrr}
0.00 & -0.07 & 0.00 \\
0.00 & 0.10 & 0.00 \\
0.00 & -0.07 & 0.00 \\
0.00 & -0.04 & 0.06 \\
0.00 & -0.04 & -0.06 \\
0.00 & -0.12 & -0.09 \\
0.00 & 0.96 & 0.00 \\
0.00 & -0.12 & 0.09 \\
0.00 & 0.00 & 0.00 \\
& 17 & \\
\text { B2 } &
\end{array}
$$

B2

1293.3151

1.5742

1.5514

8.7442

\begin{tabular}{ccr}
$X$ & \multicolumn{1}{c}{ Y } & \multicolumn{1}{c}{$Z$} \\
0.00 & 0.19 & 0.00 \\
0.00 & -0.06 & 0.04 \\
0.00 & 0.01 & 0.00 \\
0.00 & -0.06 & -0.04 \\
0.00 & -0.04 & 0.04 \\
0.00 & -0.04 & -0.04 \\
0.00 & 0.23 & 0.63 \\
0.00 & -0.23 & 0.00 \\
0.00 & 0.23 & -0.63 \\
0.00 & 0.00 & 0.00 \\
& 20 & \\
& B2
\end{tabular}

1592.1744

6.3151

9.4321

109.4327

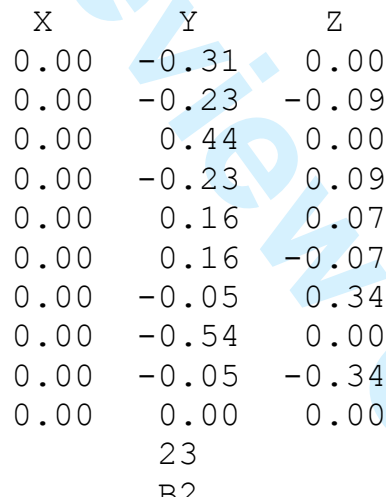

3165.6497

1.0923

6.4492

12.2231
$-0.05$

$0.00-0.02$

$0.05 \quad 0.02$

0.00

0.00

0.00

$0.61-0.30$

$0.00 \quad 0.24$

$\begin{array}{rr}-0.61 & -0.30 \\ 0.00 & 0.00\end{array}$

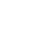

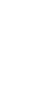

$\begin{array}{lll}X & Y\end{array}$

$\begin{array}{rrr}0.00 & 0.00 \quad 0.00\end{array}$

$\begin{array}{llll}0.00 & -0.06 & 0.03\end{array}$

$\begin{array}{rrr}0.00 & 0.00 \quad 0.00\end{array}$

$0.00 \quad-0.06 \quad-0.03$

$0.00 \quad 0.00 \quad 0.00$

$\begin{array}{lll}0.00 & 0.00 & 0.00\end{array}$

$\begin{array}{rrr}0.00 & 0.63 & -0.31\end{array}$

$\begin{array}{lll}0.00 & -0.01 & 0.00\end{array}$

0.00

0.00

0.63

0.00

0.31
0.00

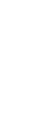

$$
\begin{array}{rrr}
0.00 & 0.07 & -0.15 \\
0.00 & 0.00 & 0.11 \\
0.00 & -0.07 & -0.15 \\
0.00 & -0.03 & -0.04 \\
0.00 & 0.03 & -0.04 \\
0.00 & -0.13 & -0.58 \\
0.00 & 0.00 & 0.11 \\
0.00 & 0.13 & -0.58 \\
0.00 & 0.00 & -0.03 \\
& 18 & \\
\mathrm{~A} 1 &
\end{array}
$$

1423.2475

2.1258

2.5370

219.3075

\begin{tabular}{ccc} 
X & \multicolumn{1}{c}{$Y$} & Z \\
0.00 & 0.00 & 0.11 \\
0.00 & -0.07 & 0.02 \\
0.00 & 0.00 & 0.06 \\
0.00 & 0.07 & 0.02 \\
0.00 & -0.10 & -0.14 \\
0.00 & 0.10 & -0.14 \\
0.00 & 0.23 & 0.63 \\
0.00 & 0.00 & 0.08 \\
0.00 & -0.23 & 0.63 \\
0.00 & 0.00 & 0.00 \\
& 21 &
\end{tabular}

$$
\text { A1 }
$$

1602.2692

4.8984

7.4093

128.9889

$\begin{array}{ccc}X & Y & Z \\ 0.00 & 0.00 & 0.06 \\ 0.00 & 0.11 & 0.32\end{array}$

$\begin{array}{llll}0.00 & 0.00 & -0.18\end{array}$

$\begin{array}{lll}0.00 & -0.11 & 0.32\end{array}$

$\begin{array}{lll}0.00 & -0.02 & -0.19\end{array}$

$\begin{array}{rrr}0.00 & 0.02 & -0.19 \\ 0.00 & -0.26 & -0.49\end{array}$

$\begin{array}{rrr}0.00 & -0.26 & -0.49 \\ 0.00 & 0.00 & -0.22\end{array}$

$\begin{array}{lll}0.00 & 0.26 & -0.49\end{array}$

0.00

$0.00 \quad 0.01$

24

A1

3209.1206

1.0965

6.6529

4.7280

$\mathrm{X}$

0.00

0.00

0.00

0.00

0.00

0.00

0.00

0.00

0.00

0.00
Y Z

$0.00 \quad 0.00$

$0.02 \quad 0.00$

$0.00-0.09$

$-0.02 \quad 0.00$
0.00

$0.00 \quad 0.00$

$0.00 \quad 0.00$

$\begin{array}{rr}-0.15 & 0.07\end{array}$

$0.00 \quad 0.97$

$0.15 \quad 0.07$

$0.00 \quad 0.00$ 


\section{5-bromo-2-chloropyrimidine}

\subsection{Geometry}

optimised Z-matrix at the b3lyp/6-311++g $(d, p)$ level of theory

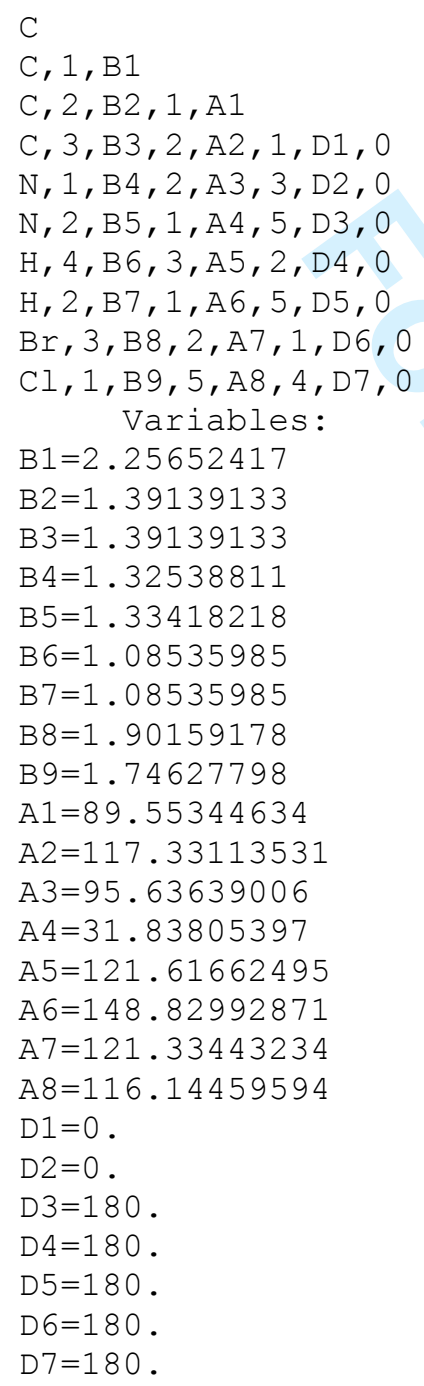

\subsection{Total Energy}

b3lyp/6-311++g $(d, p)$ level of theory

$\mathrm{E}(\mathrm{RB}+\mathrm{HF}-\mathrm{LYP})=-3297.55621429$

\subsection{Frequencies}

Output from the "b3lyp/6-311++g(d,p) freq" calculation

\begin{tabular}{|c|c|c|c|c|c|c|c|c|c|}
\hline \multirow[b]{3}{*}{ Frequ } & \multicolumn{3}{|c|}{1} & \multicolumn{3}{|c|}{2} & \multicolumn{3}{|c|}{3} \\
\hline & \multicolumn{3}{|c|}{ B1 } & \multicolumn{3}{|c|}{ B2 } & \multicolumn{3}{|c|}{ A1 } \\
\hline & -- & \multicolumn{2}{|c|}{76.3961} & \multicolumn{3}{|c|}{186.4347} & \multicolumn{3}{|c|}{271.2891} \\
\hline Red. masses & -- & 12.26 & & \multicolumn{3}{|c|}{11.4942} & \multicolumn{3}{|c|}{30.5523} \\
\hline Frc consts & -- & \multicolumn{2}{|c|}{0.0422} & \multirow{2}{*}{\multicolumn{3}{|c|}{$\begin{array}{l}0.2354 \\
0.3974\end{array}$}} & \multicolumn{3}{|c|}{1.3248} \\
\hline IR Inten & -- & 0.18 & & & & & & 0.03 & \\
\hline Atom AN & $\mathrm{x}$ & $\mathrm{Y}$ & Z & $\mathrm{x}$ & $\mathrm{Y}$ & Z & $\mathrm{x}$ & $\mathrm{Y}$ & $\mathrm{Z}$ \\
\hline 6 & 0.17 & 0.00 & 0.00 & 0.00 & 0.17 & 0.00 & 0.00 & 0.00 & -0.36 \\
\hline 6 & 0.34 & 0.00 & 0.00 & 0.00 & 0.34 & 0.08 & 0.00 & 0.06 & -0.18 \\
\hline 6 & 0.24 & 0.00 & 0.00 & 0.00 & 0.38 & 0.00 & 0.00 & 0.00 & 0.01 \\
\hline 6 & 0.34 & 0.00 & 0.00 & 0.00 & 0.34 & -0.08 & 0.00 & -0.06 & -0.18 \\
\hline 7 & 0.31 & 0.00 & 0.00 & 0.00 & 0.22 & -0.11 & 0.00 & -0.06 & -0.24 \\
\hline
\end{tabular}




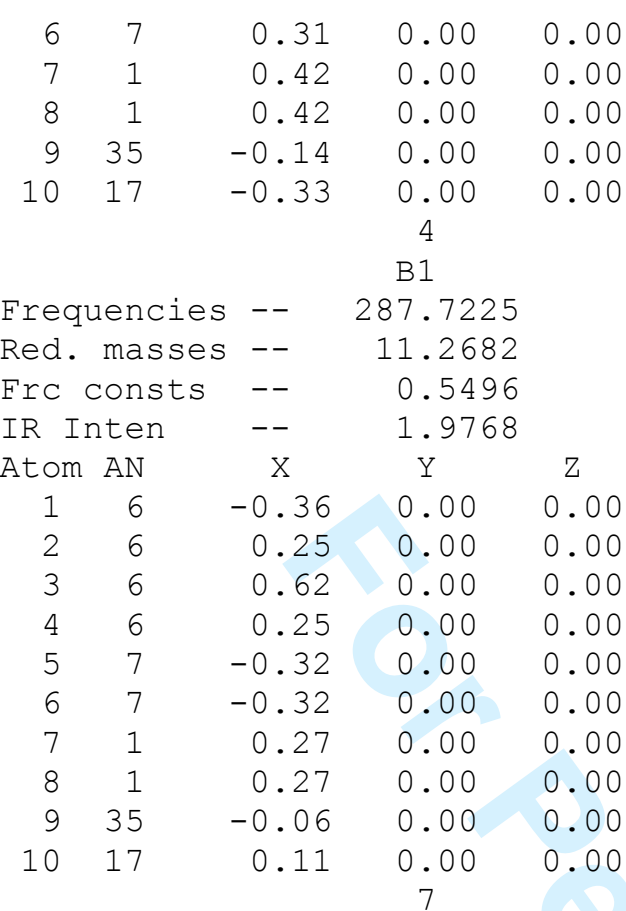

B1

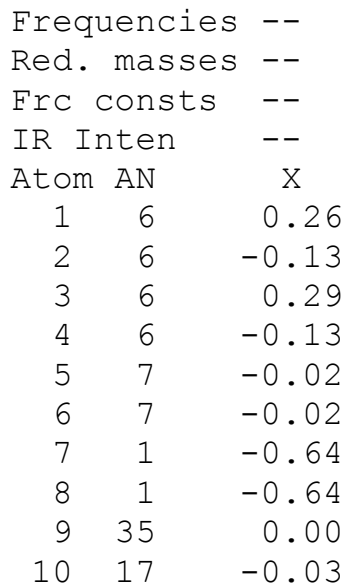

485.8950

3.1004

0.4313

2.6247

Y Z

$0.00 \quad 0.00$

$0.00 \quad 0.00$

$0.00 \quad 0.00$

$0.00 \quad 0.00$

$0.00 \quad 0.00$

$0.00 \quad 0.00$

$0.00 \quad 0.00$

0.00

0.00

0.00

10

B1

Frequencies -

Red. masses --

Frc consts --

IR Inten

Atom AN

$\begin{array}{rr}1 & 6 \\ 2 & 6 \\ 3 & 6 \\ 4 & 6 \\ 5 & 7 \\ 6 & 7 \\ 7 & 1 \\ 8 & 1 \\ 9 & 35 \\ 10 & 17\end{array}$

783.5255

9.1074

3.2942

10.9571

Y Z

$0.00 \quad 0.00$

$0.00 \quad 0.00$

$0.00 \quad 0.00$

$0.00 \quad 0.00$

$0.00 \quad 0.00$

$0.00 \quad 0.00$

$0.00 \quad 0.00$

$0.00 \quad 0.00$

$0.00 \quad 0.00$

$0.00 \quad 0.00$

13

A2

983.0345

1.3628

0.7759

0.0000

$$
\begin{array}{rrr}
0.00 & 0.22 & 0.11 \\
0.00 & 0.39 & -0.17 \\
0.00 & 0.39 & 0.17 \\
0.00 & -0.16 & 0.00 \\
0.00 & -0.27 & 0.00 \\
& 5 &
\end{array}
$$

B2

362.9228

7.4664

0.5794

4.6253

\begin{tabular}{crr}
$X$ & \multicolumn{1}{c}{$Y$} & \multicolumn{1}{c}{$Z$} \\
0.00 & 0.31 & \multicolumn{1}{c}{0.00} \\
0.00 & -0.13 & -0.20 \\
0.00 & -0.24 & 0.00 \\
0.00 & -0.13 & 0.20 \\
0.00 & 0.23 & 0.18 \\
0.00 & 0.23 & -0.18 \\
0.00 & -0.25 & 0.45 \\
0.00 & -0.25 & -0.45 \\
0.00 & 0.04 & 0.00 \\
0.00 & -0.19 & 0.00
\end{tabular}

A1

505.6901

14.7294

2.2192

32.6460

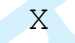

0.00

0.00

0.00

0.00

0.00

0.00

0.00

0.00

0.00

0.00

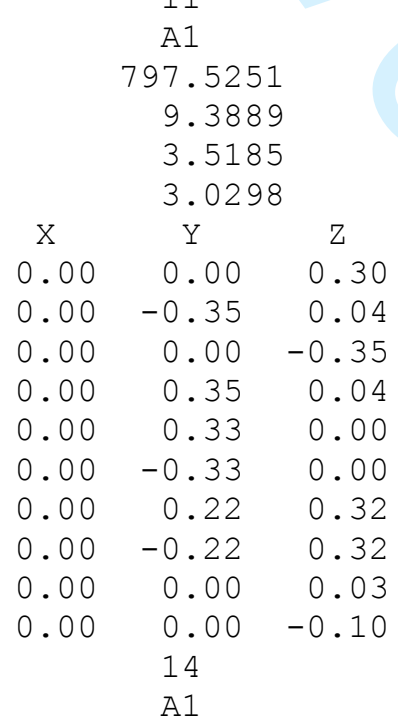

1023.6157

7.8833

4.8667

35.0351

$$
\begin{array}{llr}
0.00 & 0.06 & -0.24 \\
0.00 & 0.00 & -0.29 \\
0.00 & 0.00 & -0.29 \\
0.00 & 0.00 & 0.44 \\
0.00 & 0.00 & -0.55 \\
& 6 &
\end{array}
$$

A2

417.3407

4.2935

0.4406

0.0000

\begin{tabular}{rcc}
\multicolumn{1}{c}{$\mathrm{X}$} & $\mathrm{Y}$ & $\mathrm{Z}$ \\
0.00 & 0.00 & 0.00 \\
-0.24 & 0.00 & 0.00 \\
0.00 & 0.00 & 0.00 \\
0.24 & 0.00 & 0.00 \\
-0.28 & 0.00 & 0.00 \\
0.28 & 0.00 & 0.00 \\
0.60 & 0.00 & 0.00 \\
-0.60 & 0.00 & 0.00 \\
0.00 & 0.00 & 0.00 \\
0.00 & 0.00 & 0.00
\end{tabular}

9

B2

638.5912

9.7079

2.3325

10.7875

$\mathrm{X}$

$\mathrm{Y}$

0.00
0.00

0.00

0.00

0.00

0.00

0.00

0.00

0.00

0.00

$-0.07$

$0.19 \quad 0.00$

$0.25 \quad 0.31$

$\begin{array}{ll}-0.27 & 0.33\end{array}$

$\begin{array}{ll}-0.27 & -0.33\end{array}$

$\begin{array}{ll}0.36 & 0.11\end{array}$

$0.36-0.11$

$\begin{array}{ll}0.01 & 0.00\end{array}$

$-0.04$

12

B1

943.6251

1.4854

0.7793

8.9914

$\begin{array}{ccc}X & Y & Z \\ 0.06 & 0.00 & 0.00\end{array}$

$\begin{array}{lll}-0.13 & 0.00 & 0.00\end{array}$

$\begin{array}{lll}0.09 & 0.00 & 0.00\end{array}$

$\begin{array}{lll}-0.13 & 0.00 & 0.00\end{array}$

$\begin{array}{lll}0.00 & 0.00 & 0.00\end{array}$

$\begin{array}{lll}0.00 & 0.00 & 0.00\end{array}$

$\begin{array}{lll}0.69 & 0.00 & 0.00\end{array}$

$\begin{array}{lll}0.69 & 0.00 & 0.00\end{array}$

$\begin{array}{lll}0.00 & 0.00 & 0.00\end{array}$

$\begin{array}{lll}0.00 & 0.00 & 0.00\end{array}$

15

A1

1123.7697

3.3428

2.4872

1.7276
IR Inten --

Atom AN

Y 


$$
\begin{array}{rr}
1 & 6 \\
2 & 6 \\
3 & 6 \\
4 & 6 \\
5 & 7 \\
6 & 7 \\
7 & 1 \\
8 & 1 \\
9 & 35 \\
10 & 17
\end{array}
$$

$\begin{array}{rll}0.00 & 0.00 & 0.00 \\ 0.13 & 0.00 & 0.00 \\ 0.00 & 0.00 & 0.00 \\ -0.13 & 0.00 & 0.00 \\ 0.02 & 0.00 & 0.00 \\ -0.02 & 0.00 & 0.00 \\ 0.70 & 0.00 & 0.00 \\ -0.70 & 0.00 & 0.00 \\ 0.00 & 0.00 & 0.00 \\ 0.00 & 0.00 & 0.00 \\ & 16 & \end{array}$

A1

Frequencies -- 1189.5070

Red. masses -- $\quad 3.9208$

Frc consts -- $\quad 3.2686$

IR Inten -- 301.5755

Atom AN

$\begin{array}{rr}1 & 6 \\ 2 & 6 \\ 3 & 6 \\ 4 & 6 \\ 5 & 7 \\ 6 & 7 \\ 7 & 1 \\ 8 & 1 \\ 9 & 35 \\ 10 & 17\end{array}$

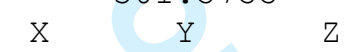

$\begin{array}{lll}0.00 & 0.00 & 0.44\end{array}$

0.00

0.00

0.00

0.00

0.00

0.00

0.00

0.00

0.00

$0.05 \quad-0.14$

$0.00 \quad 0.12$

$-0.05-0.14$

$-0.03-0.03$

$0.03-0.03$

$\begin{array}{ll}0.17 & -0.58\end{array}$

$-0.17-0.58$

$0.00 \quad 0.00$

$0.00 \quad-0.03$ 19

B2

Frequencies

Red. masses --

Frc consts --

IR Inten

Atom AN

16

26

36

46

57

$\begin{array}{ll}6 & 7\end{array}$

$\begin{array}{ll}7 & 1 \\ 8 & 1\end{array}$

$\begin{array}{rr}8 & 1 \\ 9 & 35\end{array}$

$\begin{array}{ll}10 & 17\end{array}$

1386.9337

2.1207

2.4035

6.5546

$\mathrm{x}$

0.00

0.00

0.00

0.00

0.00

0.00

0.00

0.00

0.00

0.00

0.06

$-0.04$

0.19

-0.04
-0.04

$-0.04$

$-0.39$

$-0.39$

0.00

0.00

22

A1

Frequencies -- 1582.7715

Red. masses -- $\quad 5.4647$

Frc consts -- 8.0659

IR Inten -- 43.5463

Atom AN

$\begin{array}{rr}1 & 6 \\ 2 & 6 \\ 3 & 6 \\ 4 & 6 \\ 5 & 7 \\ 6 & 7 \\ 7 & 1 \\ 8 & 1 \\ 9 & 35 \\ 10 & 17\end{array}$

$\mathrm{x}$

0.00

0.00

0.00

0.00

0.00

0.00

0.00

0.00

0.00

0.00

$$
\mathrm{Y}
$$

0.00

0.11

$$
0.00
$$

$-0.11$

$-0.04$

0.04

0.28

$-0.28$

0.00

0.00
$0^{\mathrm{Z}} \mathrm{0} 00$

0.14

0.00

$-0.14$

0.08

$-0.08$

0.55

$-0.55$

0.00

0.00

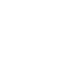

$$
\begin{array}{rrr}
0.00 & 0.00 & -0.01 \\
0.00 & 0.24 & 0.03 \\
0.00 & 0.00 & 0.36 \\
0.00 & -0.24 & 0.03 \\
0.00 & 0.38 & -0.15 \\
0.00 & -0.38 & -0.15 \\
0.00 & -0.37 & 0.29 \\
0.00 & 0.37 & 0.29 \\
0.00 & 0.00 & -0.02 \\
0.00 & 0.00 & 0.00 \\
& 17 &
\end{array}
$$$$
\text { B2 }
$$

1220.4837

11.9234

10.4644

0.6996

$\begin{array}{llll}X & Y & Z\end{array}$

$\begin{array}{lll}0.00 & 0.47 & 0.00 \\ 0.00 & -0.20 & -0.32\end{array}$

$\begin{array}{llll}0.00 & -0.20 & -0.32\end{array}$

$\begin{array}{lll}0.00 & 0.38 & 0.00\end{array}$

$\begin{array}{lll}0.00 & -0.20 & 0.32\end{array}$

$\begin{array}{llll}0.00 & -0.19 & -0.33\end{array}$

$\begin{array}{lll}0.00 & -0.19 & 0.33\end{array}$

$\begin{array}{lll}0.00 & -0.13 & 0.11\end{array}$

$\begin{array}{lll}0.00 & -0.13 & -0.11\end{array}$

0.00

0.00

0.00

0.01

0.00

20

A1

1425.7893

2.1546

2.5807

263.8659

$\begin{array}{lll}X & Y & Z\end{array}$

$\begin{array}{lll}0.00 & 0.00 & 0.11\end{array}$

$\begin{array}{lll}0.00 & -0.07 & 0.01\end{array}$

$\begin{array}{lll}0.00 & 0.00 & 0.09\end{array}$

$\begin{array}{lll}0.00 & 0.07 & 0.01\end{array}$

$\begin{array}{llll}0.00 & -0.10 & -0.14\end{array}$

$\begin{array}{lll}0.00 & 0.10 & -0.14\end{array}$

$\begin{array}{lll}0.00 & -0.23 & 0.63\end{array}$

$\begin{array}{lll}0.00 & 0.23 & 0.63\end{array}$

0.00

0.00

0.00

0.00

23

B2

3173.8549

1.0928

6.4857

1.2304

$0^{2} .08$

0.34

$-0.20$

0.34

$-0.21$

$-0.21$

$-0.48$

$-0.48$

0.00

0.00
$\mathrm{X}$

$$
\mathrm{Y}
$$

0.00

0.00

0.00

0.00

0.00

0.00

0.00

0.00

0.00

0.00
0.00

$-0.06$

0.00

$-0.06$

0.00

0.00

0.63

0.63

0.00

0.00
0.00

0.00

$$
0.00
$$

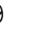

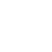

Z

0.00

0.03

0.00

$-0.03$

0.00

0.00

0.31

0.31
-0.31

0.00

0.00

$$
\begin{array}{rrr}
0.00 & 0.00 & -0.13 \\
0.00 & -0.21 & 0.04 \\
0.00 & 0.00 & 0.30 \\
0.00 & 0.21 & 0.04 \\
0.00 & 0.01 & -0.06 \\
0.00 & -0.01 & -0.06 \\
0.00 & 0.47 & -0.42 \\
0.00 & -0.47 & -0.42 \\
0.00 & 0.00 & -0.01 \\
0.00 & 0.00 & 0.02 \\
& 18 & \\
& \text { B2 } &
\end{array}
$$

1278.6112

2.0429

1.9678

9.7829

$\begin{array}{llll}X & Y & Z\end{array}$

$$
\begin{array}{rrr}
0.00 & 0.20 & 0.00 \\
0.00 & -0.07 & 0.09 \\
0.00 & 0.03 & 0.00 \\
0.00 & -0.07 & -0.09 \\
0.00 & -0.04 & 0.10 \\
0.00 & -0.04 & -0.10 \\
0.00 & 0.19 & -0.65 \\
0.00 & 0.19 & 0.65 \\
0.00 & 0.00 & 0.00 \\
0.00 & -0.01 & 0.00 \\
& 21 & \\
& \text { B2 } &
\end{array}
$$

1564.8893

7.7993

11.2531

80.5431

$\begin{array}{llll}X & Y & Z\end{array}$

$\begin{array}{lll}0.00 & 0.40 & 0.00\end{array}$

$\begin{array}{lll}0.00 & 0.25 & 0.13\end{array}$

$\begin{array}{lll}0.00 & -0.43 & 0.00\end{array}$

$\begin{array}{lll}0.00 & 0.25 & -0.13\end{array}$

$\begin{array}{llll}0.00 & -0.20 & -0.09\end{array}$

$\begin{array}{lll}0.00 & -0.20 & 0.09\end{array}$

$\begin{array}{lll}0.00 & -0.01 & 0.45\end{array}$

$\begin{array}{lll}0.00 & -0.01 & -0.45\end{array}$

$\begin{array}{lll}0.00 & 0.00 & 0.00\end{array}$

$\begin{array}{lll}0.00 & 0.00 & 0.00\end{array}$ 24

A1

3174.4721

1.0935

6.4925

4.9072

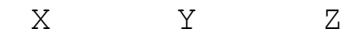

$\begin{array}{lll}0.00 & 0.00 & 0.00\end{array}$ 